\title{
LAS REGLAS DETRÁS DE LA EXCEPCIÓN. REFLEXIONES RESPECTO IDE LA TORTURA EN LOS GRUPOS DE CASOS IDE LAS TICKING TIME BOMHS
}

\author{
LUÍS GRECO
}

Ludwig Maximilians Universität

\section{Introducción}

\section{La tortura está prohibida. La causa de esta prohibición es el atentado contra la dignidad humana. Existe un amplio consenso sobre estos enunciados necesitados en sí mismos de aclaración y justificación ${ }^{1}$, de}

1 Lo primero que debería aclararse con exactitud es: qué debe entenderse bajo el concepto de tortura (así también HILGENDORF, "Folter im Rechtsstaat?", JZ, 2004, pp. 331 y ss., p. 331); hay que suponer que parece problemática la definición acuñada por la convención anti-tortura de la ONU y generalmente aceptada, según la cual la tortura sería esencialmente la causación intencional, por parte del Estado, de considerables dolores corporales o psíquicos (art. 1 ap. I párrafo 1), sobre todo, a causa de centrarse en el "dolor o sufrimiento" de una perspectiva psicológico-naturalista [de modo similar STOBBE, "Die Unmenschlichkeit der Folter", en BEESTERMÖLLER/BRUNKHORST (Ed.), Rückkehr der Folter, 2006, pp. 36 y ss., p. 40; en ese sentido, la definición existente en el art. 2 de la Convención Interamericana para la prevención y castigo de la tortura de 1985 ha sido ampliamente superior; sobre esto, BOSSUYT, "Two New Regional Conventions with Respect to the Prohibition of Torture", en MATSCHER (Ed.), Folterverbot sowie Religionsfreiheit im Rechtsvergleich, 1990, pp. 81 y ss., pp. 86-87]. Si se quiere ser consecuente, por ejemplo, es forzoso interpretar que estamos frente a un acto de tortura cuando se le afeita la cabeza a una modelo que trabaja con su cabello, lo cual le causa dolores (psíquicos) considerables y comprensibles, mientras que no lo sería la flagelación que se le causa al creyente ni al masoquista para su martirio. Las insuficiencias de la psicologización fueron vistas por la misma convención de la ONU de modo que no puede dejar de oponerse a ella, la cuestionable limitación contenida en el artículo 1 apartado I párrafo 2, según la cual los dolores resultantes de las sanciones legales no se incluyen en el concepto de tortura. Esta limitación crea nuevamente otros problemas, pues podría negarse la existencia de la tortura mediante la afirmación de que únicamente se impone la sanción prevista en la ley [la crítica fundada en la propensión al abuso de la cláusula- por ejemplo TOMUSCHAT, "Rechtlicher Schutz gegen Folter", en SCHULZ-HAGELEIT (Ed.), Alltag-Macht-Folter, 1989, pp. 95 y ss., p. 102; HILGENDORF, JZ, 2004, p. 334 -sin embargo, pasa por alto su condición insoslayable motivada por su punto de vista que psicologiza]. Sin embargo, el punto de vista determinante no podría probablemente serlo la aflicción de dolores, sino, mejor dicho, el ejercicio del dominio más absoluto que sobre una persona podría imaginarse, respecto del cual deberían jugar un rol importante, entre otras cosas, las circunstancias fácticas de ser puesto merced del Estado, en el sentido de encontrarse en posesión de éste [subrayando correctamente un aspecto central de la posesión JOERDEN, "Über ein vermeintliches Recht (des Staates), aus Menschenliebe zu foltern”, Jahrbuch für Recht und Ethik (13), 2005, pp. 495 y ss., p. 517; subraya el ejercicio del poder, sobre todo, REEMTSMA, "Wir sind alles für Dich", en REEMTSMA (Ed.), Folter, 1991, pp. 7 y ss., p. 13; véase también PARRY, "Escalation and Necessity”, en LEVINSON (Ed.), Torture - A 
Revista de Perecho

modo que en este trabajo se trata de otra cuestión, a saber: si la prohibición de la tortura, que se encuentra fundada en la dignidad humana, debe experimentar o no limitaciones en determinados grupos de casos. La intensa discusión actual gira en torno a esta cuestión: especialmente en Alemania, tras el caso Metzler-Gäfgen-Daschner*****; y en Estados Unidos, después del atentado contra las torres gemelas en Nueva York ${ }^{2}$. En Israel, por el contrario, se viene discutiendo desde hace ya casi veinte años sobre la licitud de la utilización de la tortura para la lucha contra el terrorismo ${ }^{3}$.

collection, Oxford/New York 2004, pp. 145 y ss., p. 153, en el desarrollo de la por él llamada perversidad de la tortura, esto es, su inversión de las ideas tradicionales de acción, consentimiento y responsabilidad pues la tortura tendría el significado de que el torturado, dado que él no cooperaría, se estaría, al fin y al cabo, haciendo todo a sí mismo].

En segundo lugar, debería continuarse trabajando en lo que exactamente constituye la violación real de la dignidad humana que se suele afirmar de manera muy general. Sólo, entonces, debería estimarse, por ejemplo, en qué medida la amenaza de ejercer un dolor corporal, como ocurrió en el caso Daschner, representa ya una tortura [de modo afirmativo, en general mediante una subsunción bajo el concepto de "dolor psíquico" JEßBERGER, "Wenn du nicht redest, füge ich Dir große Schmerzen zu”, Jura, 2003, pp. 711 y ss., p. 714; GAEDE, "Die Fragilität des Folterverbots", en CAMPRUBI (Ed.), Angst und Streben nach Sicherheit in Gesetzgebung und Praxis, 2004, pp. 155 y ss., p. 165; ELLBOGEN, "Zur Unzulässigkeit der Folter (auch) im präventiven Bereich", Jura, 2005, pp. 339 y ss., p. 340; JOERDEN, Jahrbuch für Recht und Ethik (13), 2005, p. 521; R. MARX, "Folter: eine zulässige Polizeiliche Präventionsmassnahme?", en GEHL (Ed.), Folter - Zulässiges Instrument im Rechtsstaat?, 2005, pp. 95 y ss., p. 102 [= KritJ (37), 2004, pp. 278 y ss.]; SCHILD, "Folter (androhung) als Straftat", en GEHL (n. 2), pp. 59 y ss., p. 61; sobre ello véase además KINZIG, "Not kennt kein Gebot?", en GEHL, (n. 2), pp. 11 y ss., p. 19 y s. y ROXIN, "Kann staatliche Folter in Ausnahmefällen zulässig oder wenigstens straflos sein?" en Festschrift für ESER, 2005, pp. 461 y ss., p. 464; EL MISMO, “Rettungsfolter?”, en Festschrift für NEHM, 2006, pp. 161 y ss., p. 169, ambos efectúan consideraciones que abren nuevas perspectivas, porque superan el psicologismo, las cuales consisten en que la amenaza del dolor y su aflicción se igualarían en el efecto del quebrantamiento de la voluntad; en contra HILGENDORF, JZ, 2004, p. 338-339, y, sobre todo, HERZBERG, "Folter und Menschenwürde", JZ, 2005, pp. 321 ss., y p. 325 y s.; KRETSCHMER, "Folter in Deutschland", RuP, 2003, pp. 102 y ss., p. 107: no hay tortura, pero sí, obviamente, un tratamiento degradante; J. SCHULZ, "Das Folterverbot der EMRK und seine Auswirkungen auf das Strafrecht", en LENZEN (coord.), Ist Folter erlaubt?, 2006, pp. 77 y ss., p. 87. Los importantes argumentos de HERZBERG demuestran, según mi parecer, muy poco la no existencia de la tortura en los casos de mera amenaza que la necesidad de despedirse justamente del punto de vista psicologicista ampliamente criticado].

***** En el caso referido el director adjunto de la policía de Frankfurt am Main, Wolfgang Daschner, había ordenado a un subordinado suyo que durante el interrogatorio (llevado a cabo el 1 de octubre de 2002) amenazara al detenido -que había secuestrado, el 27 de septiembre de 2002, a un niño de 11 años- con que si no les revelaba el lugar donde se encontraba, todavía, supuestamente con vida el niño secuestrado, se le aplicaría violencia física. El detenido, ante la amenaza, reveló el lugar donde había ocultado al niño, el cual ya había fallecido con anterioridad al interrogatorio, asfixiado por la cinta aislante con la que lo había dejado envuelto. Wolfgang Daschner defendió públicamente su postura. En junio de 2004, la Audiencia Provincial de Frankfurt am Main ordenó su procesamiento por un delito de amenazas graves. El 20 de diciembre, Wolfgang Daschner y el agente de policía que obró bajo su mando fueron condenados por amenazar con torturar a un detenido en el curso de un interrogatorio policial. [N. del T., cfr. LG Frankfurt, NJW (10), 2005, pp. 692-696; GÓNGORA MERA, ““"Ein bisschen Folter": Alemania debate sobre la tortura", disponible en http://www.menschenrechte.org/beitraege/ menschenrechte/debate tortura.htm]

2 Mayores detalles respecto a la discusión americana se encuentran en el texto que sigue. Véase R. MARX, “Globaler Krieg gegen den Terrorismus und territorial gebrochene Menschenrechte", KritJ (39), 2006, pp. 151 y ss., p. 153 y s., con respecto al punto de partida del gobierno de los EEUU relativo a la tortura.

3 Para la discusión científica fueron sobre todo centrales: el informe de la denominada Comisión Landau [resumen publicado en Israel Law Review (= IsLR) (23), 1989, pp. 146 y ss., en el cual, entre otras cosas, se emite un dictamen sobre la conformidad a Derecho de los métodos interrogatorios del denominado Servicio de Seguridad General (General Security Service, o GSS)] y, la decisión del Tribunal Superior [resumen publicado en LEVINSON (n. 2), pp. 165 y ss.]. Sobre ello, resumidamente véase EHRLICH/JOHANNSEN, "Folter im Dienste der Sicherheit?", en HASSE y otros (Ed.), Menschenrechte, 2002, pp. 332 y ss. 


\section{Revista de Derecho}

La prohibición absoluta, en sí humanitaria, puede resultar dolorosa en situaciones de necesidad. Piénsese en lo peor: una ciudad entera como Múnich, Nueva York, Barcelona o Río de Janeiro, va a desaparecer del mapamundi si no se empuja a hablar al terrorista responsable de la bomba, que acaba de ser capturado.

Semejantes grupos de casos, los denominados grupos de casos de la bomba de relojería [ticking time bomb Konstellationen], poseen a pesar de su carácter extraordinario una gran relevancia teórica, de modo que aquel que quiera aferrarse a la prohibición absoluta de la tortura, sólo en estos supuestos encontrará la ocasión de demostrar la seriedad de su afirmación. Por esa razón, en este trabajo no se seguirán las estrategias que pretenden evitar el grupo de casos de la bomba de relojería aludiendo a su carácter infrecuente ${ }^{4}$, sino que se tomará y cuestionará seriamente si en estos casos no debería afirmarse una excepción a la prohibición de torturar. Para nosotros, por tanto, no se trata de analizar el caso concreto de Frankfurt ${ }^{5}$, sino la cuestión abstracta del carácter absoluto de la prohibición de tortura. Y este carácter absoluto sólo es posible someterlo a la prueba de fuego, cuando él mismo resista ante la peor y también exija en ese caso extremo la observancia de la prohibición de torturar.

Aquí tampoco se discutirá sobre la regulación jurídico-positiva. Ésta, por un lado, rechaza de manera clara cualquier excepción a la prohibición de la tortura ${ }^{6}$, pero, por el otro, no puede sustituir una reflexión sobre los fundamentos filosófico-jurídicos.

4 Así, sin embargo, RAESS, Der Schutz vor Folter im Völkerrecht, 1989, pp. 112 y s.; KRAMER, KritJ (33), 2000, p. 624; SCHLINK, en BRUGGER/SCHLINK, Darf der Staat foltern? - Eine Podiumsdiskussion HFR 2002, Beitrag 4, p. 6; SHUE, “Torture”, en LEVINSON (n. 2), pp. 47 ss. p. 57 y s.; probablemente también ZIZEK (n. 1), p. 104 .

5 Sobre ello, véase especialmente el fallo del LG Frankfurt, NJW, 2005, p. 692 y las referencias en la siguiente nota. [N.del T. véase arriba la n.*****]

6 Subraya la claridad del Derecho positivo, por ejemplo, DÜX, ZRP, 2002, p. 180; KRETSCHMER, RuP, 2003, p. 108; JAHN, "Gute Folter - Schlechte Folter?", KritV, 2004, pp. 24 y ss., p. 35; ROXIN, "Rettungsfolter?" (n. 2), p. 163; SCHILD, "Folter einst und jetzt", en NITSCHKE (Ed.), Rettungsfolter im modernen Rechtstaat?, 2005, pp. 69 y ss., p. 80. Con respecto a la reglamentación jurídico-positiva, detalladamente (y, en parte, relacionado con el caso de Frankfurt) HECKER, "Relativierung des Folterverbots in der BRD?", KritJ (36), 2003, pp. 210 y ss., pp. 212 y ss.; JEßBERGER, Jura, 2003, pp. 712 y ss.; KRETSCHMER, RuP, 2003, pp. 102 y ss.; MERTEN, "Folterverbot und Grundrechtsdogmatik", JR, 2003, pp. 404 y ss., p. 405 y s.; WELSCH, "Die Wiederkehr der Folter als das letzte Verteidigungsmittel des Rechtsstaates?", BayVBl, 2003, pp. 481 y ss., p. 483 y s.; GAEDE (n. 2), pp. 161 y ss.; GUCKELBERGER, “Zulässigkeit von Polizeifolter?”, VBIBW, 2004, pp. 121 y ss.; JAHN, KritV, 2004, pp. 32 y ss.; NEUHAUS, "Die Aussageerpressung zur Rettung des Entführten: strafbar!", GA, 2004, pp. 521 y ss.; ZIEGLER, "Das Folterverbot in der polizeilichen Praxis", KritV, 2004, pp. 50 y ss., p. 51 y ss.; ELLBOGEN, Jura, 2005, pp. 339 y ss.; ESSER, "Die menschenrechtliche Konzeption des Folterverbotes im deutschen Strafverfahren", en GEHL (n. 2), pp. 143 y ss.; KINZIG, (n. 2), pp. 12 y ss.; NOROUZI, "Folter in Nothilfe - geboten?" JA, 2005, pp. 306 y ss.; HONG, "Das grundgesetzliche Folterverbot und der Menschenwürdegehalt der Grundrechte", en BEESTERMÖLLER/BRUNKHORST (n. 2), pp. 24 y ss.; IPSEN, "Folterverbot und Notwehrrecht", en LENZEN (n. 2), pp. 38 y ss. 
Revista de Derecho

\section{2. ¿Excepción a la prohibición de la tortura en los casos de bombas de relojería?}

Los grupos de casos de las bombas de relojería ponen claramente de relieve la fuerza explosiva de la cuestión de que se trata. No muchos consiguen resistir a la tentación que se plantea en estos casos: la de tolerar o permitir, por lo menos, en estas situaciones excepcionales, la tortura. La respuesta afirmativa de REEMTSMA a la pregunta luhmanniana de "¿haría usted eso?”7, a pesar de su firme defensa de la prohibición absoluta, es representativa de la postura de muchos dentro de la doctrina ${ }^{8}$. ROXIN, quien no abriga duda alguna sobre la antijuridicidad de cualquier tipo de acción de tortura, considera "plausible" la apreciación de una exculpación supra legal en semejantes situaciones catastróficas9. Tampoco han faltado autores que, a pesar de autodefinirse a sí mismos como opositores de la tortura, defienden una justificación para el caso de la bomba de relojería ${ }^{10}$. Entre los pocos que no dudan -correctamente, como veremos- de la existencia, en el caso extremo, de un deber de tolerar la propia muerte por convicciones morales se encuentra el profesor español MOLINA FERNÁNDEZ ${ }^{11}$.

7 LUHMANN, Gibt es in unserer Gesellschaft noch unverzichtbare Normen? 1993, p. 1, en relación a un caso de bombas de relojería.

8 REEMTSMA, Folter im Rechtsstaat, 2005, p. 122; de modo similar ZIZEK (n. 1), p. 103.

9 ROXIN, Staatliche Folter (n. 2), p. 469; también EL MISMO, Rettungsfolter? (n. 2), p. 172; EL MISMO, Strafrecht, Allgemeiner Teil, t. I, $4^{\mathrm{a}}$ ed, 2006, § 22/169; de modo similar ROBINSON, "Letter to the Editor", IsLR (23), 1989, pp. 189 y ss., p. 191; GROSS, "The Prohibitions on Torture and the Limits of the Law", en LEVINSON (n. 2), pp. 229 y ss., p. 231, 240 y s., quien describe su estrategia como la del absolutismo pragmático y desobediencia oficial; SCARRY, "Five Errors in the Reasoning of Alan Dershowitz", en LEVINSON (n. 2), pp. 281 y ss., p. 282; BIELEFELDT, "Die Absolutheit des Folterverbots", en BEESTERMÖLLER/BRUNKHORST (n. 2), pp. 109 y ss., p. 114. El defensor de la tortura DERSHOWITZ, "Is it Necessary to Apply "Physical Pressure" to Terrorists - and to Lie about it?" IsLR (23), 1989, pp. 192 y ss., p. 200, quería incialmente conceder, como máximo, sólo una disculpa. Desde una perspectiva de la teoría de sistemas intenta POSCHER, "Menschenwürde als Tabu", en BEESTERMÖLLER/BRUNKHORST (n. 2), pp. 75 y ss., p. 83 y s., elaborar la racionalidad de una prohibición sin excepción que no será respetada ante catástrofes (con modificaciones parciales, en EL MISMO, "Menschenwürde im Staatsnotstand", en LENZEN (n. 2), pp. 47 y ss., p. 61 s.; LENCKNER, en SCHÖNKE/ SCHRÖDER StGB, $27^{a}$ ed., $\S 34 / 41$ e, opinan, por otra parte, que la cuestión ni siquiera debería formularse, pues un Estado de Derecho llegaría aquí a sus límites.

10 SHUE (n. 5), pp. 57 y s.; NEUHAUS, GA, 2004, p. 525, n. 23 y p. 529 y s., quien enfáticamente intercede a favor del castigo de Daschner; JOERDEN, Jahrbuch für Recht und Ethik (13), 2005, p. 519 y pp. 522 y s., quien en general se opone a la admisión de la tortura debido a que conduciría a la ruptura del dique [N.del T. llevaría un efecto de pendiente resbaladiza], defiende, sin embargo, una causa de justificación extralegal para el caso de la bomba de relojería. Cfr. además KADISH, "Torture, the State and the Individual”, IsLR (23), 1989, pp. 345 y ss., p. 354, con la diferenciación según la cual la prohibición de la tortura sería absoluta para el Estado, pero, para el individuo solamente relativo. Es un caballo de Troya en el campo de quienes se oponen a la tortura, que nos obliga tal vez a reflexionar sobre la seriedad con la cual defendemos la prohibición a primer vista sorprendente POSNER, “Torture, Terrorism, and Interrogation”, en LEVINSON (n. 2), pp. 291 y ss., p. 296: la posición más ventajosa sería la de conservar la prohibición tradicional sin implementarla en la situación extrema (respecto de la cual deben contarse seguramente el caso de bomba y, tal vez también, el caso del secuestro).

11 Cfr. MOLINA FERNÁNDEZ, "La ponderación de intereses en situaciones de necesidad extrema: ¿es justificable la tortura?", en CUERDA RIEZU (Ed.), La respuesta del Derecho ante los nuevos retos, 2006, pp. 265 y ss., pp. 283 y s... 
Aquellos que quieren prescindir de la prohibición de la tortura, incluso de manera general, se jactan, no sin razón, de la sinceridad de su punto de vista que declara abiertamente como correctas jurídico y moralmente las alternativas de comportamiento que se percibirían efectivas y totalmente comprensibles ${ }^{12}$. Sobre todo, se acentúa que solamente se podría hacer una excepción a la prohibición de torturar en situaciones extraordinarias de necesidad, de modo que, en la mayoría de los casos, estaría vigente una prohibición casi "absoluta" de la tortura ${ }^{13}$.

\section{¿Cuáles son, sin embargo, las razones que deberían llevar a semejante solución? aquí no pueden analizarse con igual profundidad la diversidad de argumentos que se han ofrecido. Por esa razón, nos centraremos en los dos argumentos que han tenido mayor peso y difusión en la doctrina ${ }^{14}$.}

12 Así, en particular, el informe de la Comisión Landau, IsLR (23), 1989, p. 183 ("camino de los hipócritas”); DERSHOWITZ, Why Terrorism Works, New Haven/London, 2002, pp. 150 y s.; EL MISMO, "Tortured reasoning”, en LEVINSON (n. 2), pp. 257 y ss., p. 266, refiere: "La cuestión sustancial no es tanto la tortura como la responsabilidad, la notoriedad y la franqueza en una democracia que enfrenta una opción de males"; en particular, también, pp. 274 y s., DERSHOWITZ, que es conocido debido a su propuesta de una orden judicial de tortura (torture warrant) (Cfr., por ejemplo, Why terrorism works, p. 158; Tortured reasoning, p. 263). Véase, además, (DERSHOWITZ sustancialmente de acuerdo) LEVINSON, "“Precommitment" and "Postcommitment": The Ban on Torture in the Wake of September 11", Texas Law Review (81), 2003, pp. 2013 y ss., p. 2042.

13 BRUGGER, "Darf der Staat ausnahmsweise foltern?" Der Staat (35), 1996, pp. 66 y ss., p. 95: "a las prohibiciones hasta ahora absolutas se les añade una disposición excepcional para el grupo de casos aquí mencionados - ¡pero tan sólo éstos! -". Véase, además, HILGENDORF, JZ, 2004, p. 331: "sólo se trata de la cuestión de si podría torturarse "en determinados casos excepcionales estrechamente delimitados"; LEVINSON, Texas Law Review (81), 2003, p. 2031: "La cuestión es si la tortura está alguna vez en un sólo caso, justificada, no si lo es siempre o incluso con frecuencia legítima”; PARRY (n. 2), p. 159: Para ser justificable, la tortura debe ser la excepción, no la norma"; JEROUSCHEK, "Gefahrenabwendungsfolter - Rechtsstaatliches Tabu oder polizeirechtlich legitimierter Zwangseinsatz?”, JuS, 2005, pp. 296 y ss., p. 300. En contra, con razón, BIELEFELDT, “Das Folterverbot im Rechtsstaat", en NITSCHKE (n. 7), pp. 95 y ss., p. 101; véase ampliamente infra en el apartado 3.

14 Por otro lado, la comparación con el (permitido) denominado disparo mortal final [N. del T. por finaler Todesschuss o finaler Rettungsschuss -disparo final de salvamento- se califica al uso del arma de fuego destinado mortalmente por la policía en servicio para evitar el peligro de terceros. Por ejemplo, se la utiliza en las tomas de rehenes, en las cuales las negociaciones y el uso de armas no mortales no ofrecen ninguna perspectiva realista de éxito] y el entonces propuesto argumento a maiore ad minus [ante todo BRUGGER, Der Staat (35), 1996, p. 75 y s.; EL MISMO, "Vom unbedingten Verbot der Folter zum bedingten Recht auf Folter?”, JZ, 2000, pp. 165 y ss., p. 168; EL MISMO, en BRUGGER/SCHLINK (n. 5), p. 4; EL MISMO,Freiheit und Sicherheit, 2004, pp. 59 y s.; EL MISMO, "Das andere Auge. Folter als zweitschlechteste Lösung”, en NITSCHKE (n. 7), pp. 107 y ss., p. 111 y s.; siguiéndolo ISENSEE, Tabu im freiheitlichen Staat, 2003, p. 60; OTTO, "Diskurs über Gerechtigkeit, Menschenwürde und Menschenrechte”, JZ, 2005, pp. 473 y ss., p. 480] es fácil de desvirtuar, ya mediante la contestación de que el disparo mortal sería más grave que la tortura (por ejemplo, porque el disparo mortal exigiría una omisión, sin embargo, la tortura una acción positiva: WELSCH, BayVB1, 2003, p. 485; NEUHAUS, GA, 2004, p. 534; HECKER, KritJ (36), 2003, p. 215 n. 25 [de modo prudente]; JAHN, KritV, 2004, p. 43; ENDERS, "La dignidad del Estado de Derecho reside en la dignidad del ser humano -Das absolute Verbot staatlicher Folter", en NITSCHKE (n. 7), pp. 133 y ss., p. 139; o porque la tortura heriría justamente lo íntimo en el ser humano, GAEDE (n. 2), p. 184; SALIGER, “Absolutes im Strafprozeß?”, ZStW (116), 2004, pp. 35 y ss., p. 47; ROXIN, Staatliche Folter (n. 2), p. 464; EL MISMO, AT, t. I, $4^{\text {a }}$ ed., § 16/98; véase también CHRISTENSEN, "Wahrheit, Recht und Folter - Eine methodische Betrachtung", en BLASCHKE y otros (Ed.), Sicherheit oder Freiheit? 2005, pp. 133 y ss., pp. 149 y s., o también - y precisamente- mediante el resultado explicado como necesario en la n. 2 de la dimensión que lesiona específicamente la dignidad humana de la tortura y la consecuente declaración de que ello faltaría en los casos del disparo mortal [orientador aquí JOERDEN, Jahrbuch für Recht und Ethik (13), 2005, p. 517 n.90: en los casos de disparo de salvación final faltaría que el secuestrador estuviera bajo la custodia del Estado; de forma similar KREUZER, "Zur Not ein bisschen Folter?", 
En primer lugar, se argumenta que quien ha de ser torturado no es una persona ajena, sino aquél que precisamente es responsable dela situación conflictiva. "Está clara la valoración jurídica del comportamiento del extorsionista (antijurídica) y de la situación de la víctima (fiel al Derecho)"15. Una prohibición de la tortura, sin excepción, significaría que "se premiarían la sangre fría y la astucia del extorsionador"16. "Sin embargo, el Estado de Derecho no puede quedarse neutral entre el Derecho y el injusto, y debe intervenir en favor de la víctima"17. "En una situación en la que, se haga lo que se haga, hay que contar, en cualquier caso, con la barbarie, el Derecho debería ponerse del lado de la víctima y no del autor"18. "La tortura afecta a un culpable, su finalidad consiste en salvar a un inocente"19. "Si el sospechoso es realmente el terrorista que ha puesto en peligro la vida de gente inocente, la justicia dicta que sea él quien cargue con los costes de abordar ese peligro" ${ }^{20}$. Finalmente, otra forma de expresar este argumento es aludiendo a la causa de justificación de la legítima defensa en favor de terceros ${ }^{21}$, que algunos esgrimen para estos casos.

El segundo punto de vista relevante no se refiere a lo que ha hecho el sujeto que ha de ser torturado, sino a aquello que su conducta podría generar, a saber: un daño de dimensiones desastrosas. "La más grave de las torturas no es nada en comparación con la amenaza a los habitantes hecha por el extorsionador de sufrir una muerte atroz mediante la explosión de

en NITSCHKE (n. 7), p. 44; de otro modo GEBAUER “Zur Grundlage des absoluten Folterverbots", NVwZ, 2004, pp. 1405 y ss., pp. 1408 y s.: en la tortura existiría un peligro de abuso mayor].

15 BRUGGER, Der Staat (35), 1996, p. 81.

16 BRUGGER, Der Staat (35), 1996, p. 88.

17 ISENSEE (n. 15), pp. 59 y s.

18 BRUGGER, JZ, 2000, p. 173.

19 HILGENDORF, JZ, 2004, p. 335. En principio, no está claro si estas proposiciones no son una mera alusión a argumentos ajenos. Sin embargo, si se tiene en cuenta las conclusiones a las que llega el autor (338 s.: imposibilidad de la tortura, pero sólo de lega lata), parece obvio que, finalmente, hace suyas las proposiciones.

20 GUR-ARYE, "Can the War against Terror justify the Use of Force in Interrogations?", en LEVINSON (n. 2), pp. 183 y ss., p. 193.

21 ERB, en Münchener Kommentar zum Strafgesetzbuch, 2003, § 32/173 y s.; EL MISMO, Jura, 2005, pp. 24 y ss.; EL MISMO, NStZ, 2005, pp. 593 y ss.; EL MISMO, en NITSCHKE (n. 7), pp. 149 y ss., pp. 154 y s.; EL MISMO, "Folterverbot und Notwehrrecht", en LENZEN (n. 2), pp. 19 y ss., pp. 23 y ss.; FAHL, JR, 2004, pp. 186 y s.; JEROUSCHEK/KÖLBEL, "Folter von Staats wegen?”, JZ, 2003, pp. 619 y s.; MIEHE, "Nochmals: Die Debatte über Ausnahmen vom Folterverbot”, NJW, 2003, pp. 1219 y s., p. 1220; SCHAEFER, "Freibrief”, NJW, 2003, p. 947; GUR-ARYE (n. 21), pp. 191 y s.; LACKNER/KÜHL, StGB 25 a ed., 2004, § 32/17a; KÜHL, AT, $5^{\mathrm{a}}$ ed., 2005, § 7/156a; JAEGER, "Folterdebatte - es gibt kein schwarz oder weiß”, en GEHL (n. 2), pp. 29 y ss., p. 34; JEROUSCHEK, JuS, 2005, p. 300; OTTO, Grundkurs Strafrecht, $7^{\mathrm{a}}$ ed., 2004, § 8/59; EL MISMO, JZ, 2005, p. 481; BREUER, "Das Foltern von Menschen", en BEESTERMÖLLER/BRUNKHORST, (n. 2 ), pp. 11 y ss., p. 21; J. SCHULZ (n. 2), p. 87; WAGENLÄNDER, Zur strafrechtlichen Beurteilung der Rettungsfolter, 2006, p. 170. También BRUGGER, Der Staat (35), 1996, p. 83; EL MISMO, en BRUGGER/SCHLINK (n. 5), p. 8; MOORE, "Torture and the Balance of Evils," en PLACING BLAME, Oxford, 1997, pp. 670 y ss., p. 715 e ISENSEE (n. 15), p. 59, abordan este punto de vista. 
una bomba" ${ }^{22}$. La prohibición de torturar significaría "nada menos que la imposición al agredido de un deber de aceptar, sin resistencia, la destrucción antijurídica de su existencia física" ${ }^{23}$. Eso acabaría "nada menos que en una barbarie contra los intereses superiores y justificados de millones de afectados y, por lo tanto, en un escándalo ético"24. "Apenas podría imaginarse un menosprecio más claro de la personalidad de un ser humano que cuando a éste, en aras de sembrar el terror, se lo hace saltar por los aires, se lo contamina con radioactividad, envenena o infecta con gérmenes mortales." 25 "Respecto de la víctima existe una forma cualificada de lesión de la dignidad" ${ }^{26}$, esto es, la "pérdida de una posición jurídica por principio imponderable” "27. Los principios del Estado de Derecho no deberían convertirse en un "pacto suicida" 28 . "Los números importan, aún, en decisiones de principios”29. La justificación a veces mencionada a consecuencia del estado de necesidad ${ }^{30} \mathrm{o}$ de la colisión de deberes ${ }^{31}$ es una derivación del mismo pensamiento.

En principio, parece intuitivamente que los dos puntos de vista aludidos tienen sustancia y pueden justificar una excepción a la prohibición de tortura para el caso de la bomba de relojería. ¿Puede darse uno por satisfecho con ello y, con base en estas dos consideraciones, admitir únicamente la tortura en los casos de la bomba de relojería?

22 BRUGGER, Der Staat (35), 1996, p. 79.

23 ERB, Jura, 2005, p. 27.

24 TRAPP, "Individualrechte ernst - aber nicht unangemessen ernst genommen", en NIDA-RÜMELIN/ VOSSENKUHL (Ed.), Ethische und politische Freiheit, 1997, pp. 448 y ss., p. 463.

25 ERB, Jura, 2005, p. 27.

26 GÖTZ, „Das Urteil gegen Daschner im Lichte der Werteordnung des Grundgesetzes“, NJW, 2005, pp. 953 y ss., p. 956.

27 ERB, "Notwehr als Menschenrecht", NStZ, 2005, p. 597; EL MISMO, en NITSCHKE (n. 7), p. 154; EL MISMO, en LENZEN (n. 22), p. 29.

28 Esta expresión que tiene su origen en el voto particular del juez JACKSON en 337 U. S. 1, 37 (1949) es tomada por DERSHOWITZ, Terrorism (n. 13), p. 191 y también, recientemente, por BRUGGER en NITSCHKE (n. 7), p. 117. De manera similar también FAHL, JR, 2004, p. $190 \mathrm{n}$.

29 DERSHOWITZ, Terrorism (n. 13), p. 189.

30 Así en particular el informe de la Comisión Landau, IsLR (23), 1989, pp. 167 ss., pp. 184 y s., 186; y también ZAMIR, "Human Rights and National Security", IsLR (23), 1989, pp. 375 y ss., p. 395 n. 43; MOORE (n. 22), pp. 724 y s.; MIEHE, NJW, 2003, p. 1220; SCHAEFER, NJW, 2003, p. 947; PARRY (n. 2), pp. 158 y s.; JAEGER (n. 22), pp. 34 y s.; muy problamente también ZELLER, "Not actual "necessity" but possible "justification"; not "moderate" pressure, but either "unlimited" or "none at all"”, IsLR (23), 1989, pp. 201 y ss., p. 207, a pesar de contar con partes contradictorias (p. 211 y s.). Por el contrario, si bien el Tribunal Supremo Israelí habló del "estado de necesidad" -necessity defense-, sin embargo, entendió bajo ello antes una disculpa que una justificación [así también GUR-ARYE (n. 21), pp. 188 y s.; MOLINA FERNÁNDEZ, (n. 12), pp. 273 y s. habla, a mi juicio, erróneamente de justificación].

31 WITTRECK, "Menschenwürde und Folterverbot”, DöV, 2003, pp. .873 y ss., p. 877; EL MISMO, "Menschenwürde als Foltererlaubnis?", en GEHL (n. 2), pp. 37 y ss., p. 45; EL MISMO, “Achtungs- gegen Schutzpflicht? Zur Diskussion und Menschenwürde und Folterverbot”, en BLASCHKE entre otros (n. 15), pp. 161 y ss., p. 171. 


\section{Excepciones y reglas, excepciones como reglas}

La respuesta es no. Y ello por una sencilla, pero no siempre atendida, razón, a saber: que en una argumentación jurídica y moral no existen puntos de vista que sólo valgan de manera excepcional. Todo punto de vista relevante, es decir, todo punto de vista al que ante algún problema se le atribuye una relevancia moral o jurídica conserva también esta relevancia frente a todo problema equivalente. Con otras palabras: en el mundo de la argumentación jurídica y moral no existen excepciones, entendidas éstas como puntos de vistas relevantes que solamente son relevantes en un sector o ad hoc. Cada excepción es la expresión de una regla que le sirve de base, que regula, justamente, cómo debe decidirse en el caso de situaciones excepcionales. Esta regla, lamentablemente, no siempre se formula de manera explícita; pero se deduce por los datos de cualquiera de los puntos de vista que sustentan la excepción, y esto, por razones que en este trabajo no necesitan discutirse a fondo ${ }^{32}$.

¿Cuáles son las reglas que se encuentran contenidas de manera implícita en los argumentos mencionados que justifican la excepción? Si la tortura atenta contra la dignidad humana, pero debe autorizarse en los casos de las bombas de relojería, porque el candidato a la tortura ha provocado de manera responsable la situación, se ha propuesto de manera implícita la regla según la cual: la dignidad sería algo que podría perderse por el comportamiento precedente propio ("regla de la caducidad"). Aquél que se ha comportado mal pierde, a causa de su mal comportamiento, la pretensión de no ser torturado y que su dignidad humana sea respetada. Por consiguiente, la dignidad humana sería algo disponible que podría irse perdiendo según qué tipo de vida anterior se hubiera llevado o, qué tipo de hecho se hubiera realizado con anterioridad. La dignidad humana no sería en virtud de su naturaleza humana inherente per se a cualquier hombre, sino que sería algo exterior que se añade a esa naturaleza, y que,

32 Sobre un intento de fundamentación de esta pretensión de universalidad de los argumentos morales véase por ejemplo HARE, The Language of Morals, Oxford, 1952, pp. 137 y ss., pp. 158 y s.; EL MISMO, "Ethical Theory and Utilitarianism", en SEN/WILLIAMS (Ed.), Utilitarianism and Beyond, Cambridge, 1982, pp. 23 y ss., p. 25 , quien lo reconduce al significado de expresiones morales como "bien" y "deber"; HABERMAS, Diskursethik - Notizen zu einem Begründungsprogramm, en Moralbewußtsein und kommunikatives Handeln, $7^{\text {a }}$ ed., 1997, pp. 53 y ss., p. 97, quien lo declara como un presupuesto pragmático trascendental de la argumentación moral; y ALEXY, Theorie der juristischen Argumentation, 1983, pp. 234 y s., p. 237, quien lo trata como una regla fundamental del discurso práctico general. Véase extensamente, a tal efecto, WIMMER, Universalisierung en der Ethik, 1980. Últimamente el denominado "particularismo", que niega la pretensión universal de razones morales, gana seguidores de manera creciente, por ejemplo, NORRIS LANCE/LITTLE, "Defending Moral Particularism", en J. DREIER (Ed.), Contemporary Debates in Moral Theory, Malden, 2006, pp. 305 y ss., p. 307, con más referencias. Una discusión sobre esta postura superaría el marco aquí trazado. 
también, podría sujetarse a una condición resolutoria cuya verificación convertiría al afectado en un individuo de segunda categoría ${ }^{33}$. Si se acepta la regla de la caducidad también parece inexplicable qué impide oponerse a la pena de muerte ${ }^{34}$, a la castración obligatoria de delincuentes sexuales ${ }^{35} \mathrm{o}$, incluso, a los asesinatos selectivos de terroristas conocidos ${ }^{36}$. De la misma manera, no habrá razones por las que, en el trato con la criminalidad organizada, se deban respetar los derechos individuales ${ }^{37}$.

Si esta primera regla era, por tanto, de naturaleza deontológica, puesto que determinaría lo correcto con independencia de las consecuencias bajo la aplicación de consideraciones generales (o sea: el comportamiento previo del protegido por la prohibición), la segunda regla que subyace al segundo grupo de argumentos mencionados supra es consecuencialista, esto es, orientada a las consecuencias ${ }^{38}$. El segundo punto de vista en favor de la tortura, en los casos de bomba de relojería, es el que se refiere a la dimensión del daño esperable. Ahora bien, si esto resulta relevante para autorizar una lesión de la dignidad humana, se está aceptando implícitamente la siguiente regla: la dignidad sería algo que únicamente debe respetarse en tanto que los costes de este respeto no sobrepasen un determinado umbral de importancia ("regla de los costes"). Si los demás tuvieran un interés suficientemente intenso en que no se respetara la dignidad de un sujeto, el menoscabo de esta última estaría permitido. Por consiguiente, no existiría un ámbito nuclear de la personalidad humana que estuviera protegido contra las intromisiones gobernadas por intereses ajenos. Todo ser humano podría ser utilizado e instrumentalizado para fines ajenos, suponiendo que los demás consideren estos fines como suficientemente valiosos. Si se ha admitido

33 De forma muy clara MOORE (n. 22), p. 719: "si el bote salvavidas se esta hundiendo y alguien debe ir a salvar al resto, los asesinos conocidos entre los pasajeros son buenos candidatos para ser los primeros en ser lanzados al agua".

34 Acertadamente visto por HECKER, KritJ (36), 2003, p. 217. En verdad, la muerte per se no es aún un atentado contra la dignidad. Lo que hace absolutamente inaceptable a la pena de muerte no es, sin embargo, la muerte, sino la situación en la que ésta tiene lugar, a saber, una situación en la cual alguien se encuentra detenido por el Estado, entregado completamente indefenso a su merced.

35 Realzado por LÜDERSSEN, "Die Folter bleibt Tabu”, en Festschrift für RUDOLPHI, 2004, pp. 691 y ss., p. 702; de modo similar MOLINA FERNÁNDEZ (n. 12), p. 281.

36 Extremo que es justificado de manera consecuente por DERSHOWITZ, Terrorism (n. 13), p. 183.

37 Rotundo, por el contrario, en ese caso TRAPP (n. 25), pp. 470 y s., que desde el punto de partida de una variante del utilitarismo desarrollada por él califica a estos derechos de "fundamentalista-liberales".

38 Respecto a la distinción entre consecuencialisimo y deontologicismo cfr. BIRNBACHER, Analytische Einführung in die Ethik, 2003, p. 113 y ss.; NEUMANN, "Moralphilosophie und Strafrechtsdogmatik", ARSP (44), 1991, pp. 248 y ss., pp. 250 y s.); EL MISMO, "Die Moral des Rechts", Jahrbuch für Recht und Ethik (2), 1994, pp. 81 y ss., pp. 82 y s. Según LÜBBE, “Konsequenzialismus und Folter”, en LENZEN (n. 2), pp. 67 y ss., p. 70 , el deontológico debería ser el argumento central del defensor de la tortura. Esto podría ser correcto sólo a medias, como se explicará más abajo. 
esta regla de los costes, ya no hay razones por las que solamente se deba torturar al terrorista y no también, por ejemplo, a sus hijos ${ }^{39}$ a fin de que aquél hable.

Todavía no se ha demostrado que las dos reglas que se acaban de analizar sean incorrectas. Hasta el momento, se ha desarrollado un argumento de coherencia más modesto en la verificación de que no es posible compatibilizar estas reglas con otras reglas que son constitutivas y fundamentales para nuestra comprensión tradicional del Derecho. Nuestra tradición se basa, justamente, en que existe algo como una dignidad inalienable y unos derechos humanos inalienables que no se le pueden denegar ni al peor de los canallas ${ }^{40}$, y que, el individuo, no se encuentra ni a disposición de la utilidad del Estado ni tampoco a merced de la del conciudadano ${ }^{41}$. Mientras uno quiera aferrarse a estos principios debe calificarse a la tortura de inadmisible -también y precisamente en las situaciones excepcionales $-{ }^{42}$.

Muchos de los defensores de la aquí rechazada solución flexibilizadora o, cuando menos, muchos de sus simpatizantes podrían acobardarse ante semejante ruptura con los principios establecidos. No es una casualidad que las dos reglas arriba expresadas prácticamente nunca se expresen de manera abierta y que el tópico del Derecho penal del enemigo, de carácter afirmativo y legitimador, que también podría entenderse, por lo menos, como un intento de articular ambas reglas, ha ya provocado, en general, fundada indignación ${ }^{43}$. Como ya he afirmado, se intenta

39 Así también KREMNITZER, “The Landau Commission Report”, IsLR (23), 1989, pp. 216 y ss., p. 234; MARX (n. 2), pp. 119 y s.; MOLINA FERNÁNDEZ (n. 12), p. 280; véase el caso del terrorista, Mohammed, de alto rango de Al-Qaeda, apresado por los EEUU [para más detalles, DERSHOWITZ, Terrorism (n. 13), p. 270].

40 Véase, por ejemplo, DÜRIG, "Der Grundrechtssatz von der Menschenwürde“, AöR (81), 1956, pp. 117 y ss., p. 126; BADURA, "Generalprävention und Würde des Menschen", JZ, 1964, pp. 337 y ss., p. 341; HÄBERLE, „Die Menschenwürde als Grundlage der staatlichen Gemeinschaft“, en ISENSEE/KIRCHHOF (Ed.), Handbuch des Staatsrechts, t. I, 1987, § 20/44; BVerfGE 87, 228.

41 Por todos DÜRIG, AöR (81), 1956, pp. 127 y ss. (llamada Objektformel); BVerfGE 87, 228.

42 Muy similar R. MARX (n. 2), p. 121.

43 Con respecto al Derecho penal del enemigo véase JAKOBS, "Bürgerstrafrecht und Feindstrafrecht", HRRS, 2004, pp. 88 y ss.; EL MISMO, Terroristen als Personen im Recht?, ZStW (117), 2005, pp. 839 y ss.; respecto a ello en general y de manera crítica GRECO, "Über das sogenannte Feindstrafrecht", GA, 2006, pp. 96 y ss., pp. 104 y s.; ROXIN, AT, t. I, § 2/127 y s.; SALIGER, "Feindstrafrecht: Kritisches oder totalitäres Strafrechtskonzept?", JZ, 2006, pp. 756 y ss.; SCHÜNEMANN, "Feindstrafrecht ist kein Strafrecht", Festschrift für NEHM, 2006, pp. 219 y ss. son acertados conexiones entre el topos del Derecho penal del enemigo y el esfuerzo para la legitimación de la tortura por GAEDE (n. 2), pp. 175 y s.; JAHN, Das Strafrecht des Staatsnotstandes, 2004, p. 234; FRANKENBERG, "Kritik des Bekämpfungsrechts", KritJ (38), 2005, pp. 370 y ss., pp. 383 y s.; BIELEFELDT (n. 14), pp. 103 y s.; BEESTERMÖLLER, "Folter - Daumenschrauben an der Würde des Menschen", en BEESTERMÖLLER/BRUNKHORST (n. 2), pp. 115 y ss., p. 115; BRUNKHORST, "Folter, Würde und repressiver Liberalismus", en BEESTERMÖLLER/BRUNKHORST (n. 2) pp. 88 y ss., pp. 92 y s., y también por JAKOBS, ZStW (117), 2005, p. 849 en su reciente toma de posición ambigua, como mínimo no crítica, según la cual el Estado en el interrogatorio de los terroristas debería rebasar los límites del § 136a StPO. 
vender la opinión según la cual se trataría simplemente de eso: de prever una excepción para un caso excepcional ${ }^{44}$. Sin embargo, un defensor de la opinión criticada podría atreverse a dar el paso y a aceptar, sin más ocultación, una o las dos reglas arriba expuestas. Frente a él ya no sería suficiente el argumento de coherencia hasta el momento expuesto, de modo que resulta forzoso explicar por qué ambas reglas también son, en sí mismas, erróneas.

\section{Crítica a la regla de la caducidad}

La dignidad puede perderse: así reza la primera regla. Ya se ha explicado que esto no se corresponde con nuestra comprensión de dignidad. Sin embargo, lo que ahora se trata de demostrar es que hay que mantener nuestra comprensión de dignidad, que no es defendible una modificación de nuestro concepto. A fin de cuentas, debería irse hasta los fundamentos de la filosofía política para indagar en los motivos que sustentan la prohibición del menosprecio a la dignidad mediante la tortura. Sin embargo, en este marco limitado, solamente se puede hacer un esbozo de esta cuestión.

El Estado ejerce el monopolio de la violencia sobre un territorio determinado. Con otras palabras, él es la instancia superior de poder en un determinado territorio. En ese sentido, todavía no se diferencia de la gran banda de ladrones agustiniana, puesto que ésta es la instancia más poderosa en un espacio determinado. El Estado, sin embargo, sostiene que se diferencia de la banda de ladrones, porque, según afirma, no ejerce sólo el poder, sino el poder legítimo. Sin embargo, es necesario que el Estado fundamente tal afirmación desde una perspectiva jurídica y moral. Con otras palabras: el Estado debe presentar un título que explique que el poder que detenta es, desde el punto de vista jurídico y moral, un poder legítimo.

Tiempo atrás, los Estados hacían valer como título, por ejemplo, un mandato divino o una tradición familiar. En casos conocidos, aunque

44 Véase referencias supra n. 14. Junto a la estrategia del silencio sobre las dos reglas elaboradas es muy común también su injustificada negación, por ejemplo, OTTO, JZ, 2005, p. 481: "pero él (el torturado) tampoco quedaría privado de derechos debido a su comportamiento". También es poco claro el informe de la Comisión Landau, IsLR (23), 1989, p. 184, que si bien refiere que "organizaciones que se fijan esto (el terrorismo) como su objetivo no tienen el derecho moral de reclamar que el Estado mantenga por su parte respecto a ellas los derechos civiles corrientes", sin embargo, en la siguiente oración reitera el compromiso de respeto a los derechos humanos. Entre los pocos que mencionan claramente la regla de la caducidad están BREUER (n. 22), p. 22, y JAKOBS, ZStW (117), 2005), p. 843 n. 8. 
por suerte excepcionales, el título fue incluso la llamada a la fundación de una sociedad depurada racialmente o a la de una sociedad sin propiedad privada. El Estado actual, bajo cuyo poder vivimos, exhibe otro título: afirma hablar en nuestro nombre. Por consiguiente, ya no apela a Dios o a la tradición, sino a los mismos destinatarios del ejercicio de su poder para demostrar sus derechos, para vincular por tanto a estos destinatarios desde el punto de vista jurídico y moral.

Para que la legitimidad del Estado se convierta en algo más que una simple afirmación, éste debe tomar realmente en serio, como tal, a aquél en cuyo nombre pretende hablar. Esto no significa que el Estado también debe considerar con cierto alcance aquello que los ciudadanos quieren, sino que debe tener en cuenta - fundamentalmente- el mero hecho de que los ciudadanos sean capaces de querer, es decir, que tienen voluntad. El título de legitimidad estatal presupone que existen seres humanos que tienen voluntad y que, el Estado, como mínimo, toma buena nota de esta realidad elemental. Una representación en la cual de ninguna manera puede reconocerse al representado, porque éste ni siquiera es considerado como titular de una voluntad, no es justamente una representación. En consecuencia, una relación en estos términos no crea ningún deber moral o jurídico de respetar las medidas provenientes de la instancia de poder, puesto que, precisamente, respecto a los representados, se estaría ante algo tan ajeno como cuando se está frente a las acciones de una banda de ladrones.

Para aclarar esto: el Estado no promete cumplir con cualquier contenido de la voluntad de sus ciudadanos. Ello, además, no sería adecuado entre un Estado y sus ciudadanos, sino más bien entre una abuela y su nieto mimado. El Estado no promete tomar en serio el contenido de la voluntad, sino el propio hecho de que los ciudadanos tienen voluntad. Esto es lo más fundamental y es la clave de que tanto la tortura esté prohibida como de que ningún comportamiento precedente incorrecto pueda derogar esta prohibición.

A partir de estas modestas reflexiones se deduce, luego, la inadmisibilidad de la tortura: la tortura aniquila la condición del ser humano, precisamente, de tener una voluntad, que es presupuesto, como se ha dicho, para el ejercicio legítimo del poder ${ }^{45}$. Si esto se

45 De modo similar ENDERS (n. 15), p. 142; MARX (n. 2), pp. 118 y s.; con más detalle también BRUNKHORST (n. 44), pp. 92, 99 y REEMTSMA (n. 9), p. 125, quienes ven en la destrucción de la voluntad del ciudadano 
comprende bien, no se trata entonces de que alguien deba sufrir algo que no quiere, sino de que alguien sea sometido a un trato que aparece como algo completamente indiferente frente al hecho de que él es capaz de tener voluntad. La tortura elimina la voluntad e, incluso, lo hace de manera completa, de modo que aquél que es torturado se encuentra $e o$ ipso como alguien en cuyo nombre el Estado ya no puede hablar más. La tortura está prohibida porque es un acto de exclusión, porque excluye al individuo del círculo donde se encuentran los ciudadanos en cuyo nombre habla el Estado.

A pesar de ello, cabría preguntarse si el ciudadano no podría autoexcluirse ${ }^{46}$; si no podría tenerse en cuenta su voluntad de no ser ya representado por el Estado, viéndose en su comportamiento antijurídico previo una causa para torturarlo. Pero esto obviamente no es así. Como se afirmó, lo malo en la tortura no es que ella no sea compatible con el contenido de lo querido, sino que ella pasa por alto, desconsideradamente, el hecho de que en absoluto puede ser querida. El Estado declara, por medio de la tortura, que la voluntad no le interesa en absoluto. Por eso, parece contradictorio centrarse en el contenido de la voluntad -ila misma voluntad que, independiente del contenido, es declarada, ya como tal, como irrelevante ante la tortura!- y esperar ante él la caducidad de la pretensión de no ser torturado.

Además, como argumento adicional, frente a la regla de la caducidad, podría aducirse que, a las circunstancias que hacen tan poco probable el caso de la bomba de relojería, pertenece, y no en último lugar, la de que se haya descubierto el terrorista que había puesto la bomba. Conforme la regla de la caducidad no queda claro quién debe ser considerado responsable. Partiendo de las reglas jurídico-penales de imputación de responsabilidad no sólo quien ha puesto la bomba puede perder su pretensión de no ser torturado, sino también todo partícipe, fuese como inductor o como cómplice y, también, finalmente, cualquiera que tenga conocimiento. Quien tenga conocimiento de dónde se encuentra la

justamente un socavamiento de las condiciones del ejercicio del poder legítimo. Estas relaciones las desconoce ERB, en NITSCHKE (n. 7), p. 162; EL MISMO, en LENZEN (n. 22), p. 32, que ve en la tortura no más que una coacción ejecutada mediante vis compulsiva. En la misma línea que aquí se desarrolla, pero, de modo insuficiente SPIRAKOS, Folter als Problem des Strafrechts, 1990, p. 196 quien considera la "participación en el Estado" el bien lesionado por la tortura lo que, sin embargo, debería obligarlo a llegar a la conclusión (por él negada, p. 229 s.) de que pudiera torturarse tan pronto como exista el peligro de que el Estado dejase de existir y ya no se pudiera participar en él.

46 JAKOBS, ZStW (117), 2005, p. 849, en sus últimas declaraciones respecto al Derecho penal del enemigo más bien se centra en este punto: la exclusión del terrorista sería una autoexclusión. De acuerdo POLAINO-ORTS, Derecho Penal del Enemigo, Lima, 2006, pp. 97, 99 y s., 102, 106: "Se es enemigo, porque se quiere serlo". 
bomba, pero sin ser garante -así, el aliado que no participa, el abogado o, incluso, la novia o la madre del terrorista-, si bien no interviene en la explosión ni como autor ni como partícipe, sin embargo, es aún responsable en un sentido determinado, o sea, a causa de su omisión del deber de socorro. Por este motivo, los defensores consecuentes de la doctrina de la caducidad han afirmado que sería admisible torturar a semejantes sujetos que tengan conocimiento de la situación ${ }^{47}$. Finalmente, es cuestionable si entonces la admisibilidad de la tortura depende en realidad del comportamiento previo, puesto que se tendría permiso de torturar prácticamente a todo sujeto que no ha intervenido, tan pronto como se supiera que éste podría evitar las malas consecuencias ${ }^{48}$. Porque, cualquiera, y no solamente quien colocó la bomba puede ser "responsable", cualquiera, y no sólo quien colocó la bomba puede perder su dignidad y ser torturado también. Entonces, el argumento de la pérdida de la dignidad cae prácticamente ad absurdum, puesto que comienza deontológicamente con la cuestión de la responsabilidad para, sin embargo, no diferenciarse prácticamente en el resultado de una postura consecuencialista que se apoya exclusivamente en los costes. En una postura consecuencialista tampoco se torturaría a una persona que no supiera cómo puede evitarse el daño, pues una medida como ésta de nada serviría para evitar la catástrofe.

El argumento decisivo en contra de la regla de la caducidad reza en consecuencia: que la negación fundamental de la voluntad no se puede justificar por medio de ninguna naturaleza de voluntad. En consecuencia, la regla de la caducidad no sólo es falsa, sino también y, sobre todo, hipócrita, porque finge observar la voluntad del torturado, para someterla, justamente, a la negación más profunda. Como argumento adicional no puede pasar por inadvertido que difícilmente pueden trazarse límites en la doctrina de la caducidad de la dignidad, puesto que no es solamente responsable el terrorista, sino finalmente también cualquiera que tenga conocimiento (por causa de la omisión del deber de socorro).

47 Así, en particular, MOORE (n. 22), p. 717; en contra, GUR-AYRE (n. 21), p. 193. De modo similar propone DERSHOWITZ, Terrorism (n. 13), pp. 174 y s., abandonar la diferenciación de Derecho internacional entre combatientes y no combatientes, de modo que cualquiera que sacara provecho del terrorismo o en él se apoya debería soportar los costes de su lucha (en contra, con razón, el ya bastante concesivo IGNATIEFF, The Lesser Evil. Political Ethics in an Age of Terror, Edinburgh, 2005, p. 94).

48 El único grupo de casos en los cuales surge una diferencia es en el de personas que tienen conocimiento y son irresponsables -por ejemplo la hija de 12 años del terrorista que conoce todo-. Porque las personas irresponsables lo son, con frecuencia, a causa de motivos intelectuales, aunque la importancia práctica de esta diferencia podría ser insignificante. 


\section{Crítica a la regla de los costes}

Una crítica más profunda a la regla de los costes se ha logrado ver, con más detalle, ya en el punto 4. Esta coloca el respeto de la dignidad humana bajo una reserva de costes y, esto, no es compatible con el pensamiento de que el Estado, en el ejercicio de su poder, pretende actuar en nombre de todos los destinatarios. Una reserva de costes para el respeto de la dignidad humana no significa otra cosa que la renuncia a esta idea que consiste, justamente, en que hay un valor intrínseco en el ser humano, el cual es completamente independiente de los intereses de los demás. Con otras palabras, el respeto ante la dignidad humana es una consideración deontológica (en sentido kantiano) que, por tanto, es completamente independiente de la consideración de las buenas y malas consecuencias de su respeto ${ }^{49}$. Ya el establecimiento de la segunda regla infringe esta

49 Esto lo explica claramente NEUMANN, "Die Tyrannei der Würde", ARSP (84), 1998, pp. 153 y ss., p. 154 , y HRUSCHKA, "Die Würde des Menschen bei Kant”, ARSP (88), 2002, pp. 463 y ss., (pp. 478 y s.: La incompatibilidad entre la dignidad y el consecuencialísimo), y con relación directa al problema de la tortura GAEDE (n. 2), pp. 173 y s.: "Para el utilitarismo no es posible pensar algo absoluto en el sentido de un Derecho absoluto" y JAHN, KritV, 2004, p. 47. En esta línea, también HASSEMER, "Unverfügbares im Strafprozeß”, en Festschrift für MAIHOFER, 1988, pp. 183 y ss., pp. 200 y s.. Por eso mismo, de manera consecuente TRAPP (n. 25), p. 459; EL MISMO, "Wirklich Folter oder nicht vielmehr selbstverschuldete Rettungsbefragung?", en LENZEN (n. 2), pp. 95 y ss., pp. 97, 113 y ss. y JOERDEN, Jahrbuch für Recht und Ethik (13), 2005, p. 515, quienes a causa de sus perspectivas utilitaristas no admiten reglas o derechos sin excepción, y BRUGGER, JZ, 2000, p. 172; EL MISMO, Das anthropologische Kreuz der Entscheidung in Politik und Recht, 2005, pp. 166 y s., quien en sus publicaciones más tardías profesa expresamente el consecuencialísimo. Véase ya la defensa de la tortura realizada por BENTHAM, "Of Torture; Of Compulsion and herein of Torture", en TWINING/TWINING, Northern Ireland Legal Quarterly 24 (1973), p. 305 ss., pp. 312 y s., 330 y s..

Los autores que hablan de un conflicto de "dignidad contra dignidad" [así BRUGGER, Der Staat (35), 1996, pp. 79 y s.; EL MISMO, Menschenwürde, Menschenrechte, Grundrechte, 1997, pp. 23 y s.; EL MISMO, JZ, 2000, p. 169; EL MISMO, en BRUGGER /SCHLINK (n. 5), p. 4; EL MISMO, Freiheit (n. 15), pp. 61, 63 y s.; EL MISMO, en NITSCHKE (n. 7), p. 112; ISENSEE (n. 15), p. 59; WITTRECK, DöV 2003, pp. 878 y s.; EL MISMO, en GEHL (n. 2), pp. 50 y ss; EL MISMO, en BLASCHKE (n. 15), pp. 177 y s. (con una contra crítica no convincente pp. 179 y s.), quien afirma una lesión a la dignidad sobre la perspectiva de la víctima, no ya en el peligro para su vida; GÖTZ, NJW, 2005, p. 955; WAGENLÄNDER (n. 22), p. 167; aparentemente también BIRNBACHER, "Ethisch ja, rechtlich nein - ein fauler Kompromiss?”, en LENZEN (n. 2), pp. 135 y ss., pp. 142, 145 y 147; una solución diferenciadora STEINHOFF, "Warum Folter manchmal moralisch erlaubt, ihre Institutionalisierung durch Folterbefehle aber moralisch unzulässig ist", en LENZEN (n. 2), pp. 173 y ss., p. 185, quien hace valer el argumento solo para la corrección moral del torturador no la corrección jurídica; continúa LENZEN, “"Folter”, Menschenwürde und das Recht auf Leben”, en LENZEN (n. 2), pp. 200 y ss., pp. 210 y ss., quien incluso considera prioritaria frente a la dignidad del autor el derecho a la vida de la víctima] desconocen que la dignidad no es un estado -consecuencialistabueno, cuya maximización trata de perseguirse, sino una limitación deontológica a la persecución de cualquier estado bueno. Si la deontología pudiera fundamentar después de todo deberes de acción y, no sólo, deberes de omisión (a favor de ello por ejemplo HÖFFE, Kategorische Rechtsprinzipien, 1990, p. 189), luego deberían tener prioridad, en caso de conflicto, los deberes de omisión (así relacionado con el caso de la tortura MERTEN, JR, 2003, p. 407; WELSCH, BayVB1, 2003, p. 484; NEUHAUS, GA, 2004, p. 533; SALIGER, ZStW (116), 2004, p. 47; SCHILD (n. 2), p. 72; WOLBERT, “Ausnahmsloses Verbot der Folter?”, en GEHL (n. 2), pp. 93 y s.; siguiendo ello MARX (n. 2), pp. 120 y s., y ROXIN, Staatliche Folter (n. 2), p. 466; EL MISMO, Rettungsfolter (n. 2), p. 164; EL MISMO, AT, t. I, $4^{a}$ ed., § 16/99: Los deberes de protección persisten únicamente en el marco de lo posible del Estado de derecho). Además es importante la advertencia jurídico-positiva debida a HONG (n. 7), p. 26, y CHRISTENSEN (n. 15), p. 138, según la cual los deberes de protección por sí solos tampoco generan ningún fundamento legal para validar la ingerencia en la libertad de los ciudadanos -Eingriffsgrundlage-. Cfr. también en este sentido, incluso sin relación con la discusión sobre la tortura, WAHL/MASING, "Schutz durch Eingriff”, JZ, 1990, pp. 553 y ss., pp. 557 y s.

La estructura deontológica del argumento de la dignidad humana desacierta también en las apreciaciones que quieren 
comprensión, puesto que se intenta reinterpretar la dignidad humana de modo consecuencialista, por tanto, dependiente de las consecuencias.

Aunque uno podría darse teóricamente por satisfecho con esta aclaración, supongamos, no obstante, ad argumentandum, que las cosas fueran como afirman los partidarios de la excepción, de modo que la dignidad humana pudiera dejarse de respetar para evitar daños importantes o quizás sólo catastrofales: ¿Se seguiría de ello que la tortura es admisible en grupos de casos como los precisamente aquí discutidos?

$\mathrm{Al}$ respecto presentan dudas considerables -en contra de los defensores de una excepción a la prohibición de tortura-. En principio, se encuentra fuera de dudas que la no evitación de la explosión de la bomba tendría como consecuencia un daño increíble. La valoración de los defensores de la tortura, según la cual este daño sería más grande que aquél que se produciría por medio de la autorización de la tortura, parece, sin embargo, contemplando la cuestión más de cerca, altamente problemática. Esta suposición que se vende como empírica resulta ser ampliamente ideológica. Aquí es el lugar en el que debería escucharse el repetidamente invocado peligro de la ruptura del dique ${ }^{50}$. La admisión de la tortura, también para una situación excepcional, significa la rehabilitación de una estrategia de superación de un problema que sería mejor que continuara desterrada del ámbito de lo que debe ser considerado.

determinar el contenido de la dignidad del ser humano mediante la ponderación (por ejemplo SCHLEHOFER, "Die Menschenwürdegarantie des Grundgesetzes - absolute oder relative Begrenzung staatlicher Strafgewalt?", GA, 1999, pp. 357 y ss., pp. 362 y s.; NEUHAUS, GA, 2004, pp. 529 y s.; JEROUSCHEK/KÖLBEL, JZ, 2003, p. 618; HERZBERG, JZ, 2005, pp. 323 y s., en particular p. 324, o conciben la prohibición deontológica referida a la dignidad como resultado de una "ponderación de segundo nivel" (así SALIGER, ZStW (116), 2004, p. 65), o la entienden como un ideal que debe ser alcanzado [WETZ, "Die Würde des Menschen - Ein Phantom?", ARSP (87), 2001, pp. 311 y ss., p. 323].

50 KREMNITZER, IsLR (23), 1989, pp. 260 y s.; RAESS (n. 5), pp. 112 y s.; MORGAN, “The Utilitarian Justification of Torture", Punishment and Society (2), 2000, pp. 181 y ss., pp. 191 y ss.; EHRLICH/JOHANNSEN (n. 4), pp. 358 y s.; ZIZEK (n. 1), p. 104; HAURAND/VAHLE, "Rechtliche Aspekte der Gefahrenabwehr in Entführungsfällen”, NVwZ, 2003, pp. 514 y s., p. 521; KRETSCHMER, RuP, 2003, p. 114; WELSCH, BayVBl, 2003, p. 485; GEBAUER, NVwZ, 2004, pp. 1408 y s.; ZIEGLER, KritV, 2004, p. 62; GROSS (n. 10), pp. 234 y s.; ELLBOGEN, Jura, 2005, p. 342; GUSY, “Christian Thomasius: Über die Folter, 1705”, NJW, 2005, pp. 239 y ss., p. 240; KREUZER (n. 15), p. 44; MARX (n. 2), pp. 113 y s.; ROXIN, Staatliche Folter (n. 2), pp. 467 y s.; EL MISMO, Rettungsfolter? (n. 2), pp. 171 y s.; K. GÜNTHER, "Darf der Staat foltern, um Menschenleben zu retten?", en BEESTERMÖLLER/BRUNKHORST (n. 2), pp. 101 y ss., pp. 106 y s.; HASSEMER, "Sicherheit durch Strafrecht”, StV, 2006, pp. 321 y ss., p. 330; MOLINA FERNÁNDEZ (n. 12), pp. 280 y s.; VON DER PFORDTEN, "Ist staatliche Folter als fernwirkende Nothilfe ethisch erlaubt?", en LENZEN (n. 2), pp. 149 ss., p. 168; POSCHER, Menschenwürde (n. 10), pp. 50 y ss., p. 53; STEINHOFF (n. 50), pp. 194 y ss.; también JAHN (n. 44), p. 255 y WOLBERT (n. 50), pp. 90 y s.; que estos peligros suministran, a lo sumo, un argumento adicional, lo subrayan correctamente GAEDE (n. 2), 190 y BIELEFELDT (n. 10), pp. 112 y s. 
En primer lugar, sorprende que esto pase por inadvertido a casi ${ }^{51}$ todos los defensores de la flexibilización de la prohibición de tortura ${ }^{52} \mathrm{o}$ que, en el mejor de los casos, sea contestado con argumentos muy naífs ${ }^{53}$. Sin embargo, esa actitud puede comprenderse después de reflexionar sobre la carga emocional -o quizás, mejor dicho, ideológica- del ejemplo de la bomba de relojería. Por tanto, el ejemplo no es problemático porque señale una situación extraordinaria ${ }^{54}$, tampoco porque nos obligue retóricamente a tomar una apremiante decisión irreflexiva como si pudiera escucharse el tictac de la bomba ${ }^{55}$. En realidad, lo problemático es que, a pesar de la bandera consecuencialista por él llevada, induce a una infracción de un principio fundamental de la tradición ética consecuencialista más importante, o sea, del utilitarismo: el principio de imparcialidad ${ }^{5}$. Nosotros sufrimos los daños que deben esperarse de la bomba de relojería ${ }^{57}$; los daños esperables de la tortura afectan a otros. Incluso, mediante el agravamiento de la cuestión por una situación de decisión extrema se desplaza la mirada a otros daños que pueden derivarse de la autorización de la tortura para otras situaciones diferentes no tan extremas. Las consecuencias que al final se consideran en el análisis de coste-beneficio se reducen precipitadamente a la explosión que se origina directamente. Desde semejante perspectiva parcial parece realmente

51 Las pocas excepciones son JEROUSCHEK/KÖLBEL, JZ, 2003, pp. 618 y s. (pero de manera diferente JEROUSCHEK, JuS, 2005, pp. 301-302), y JOERDEN, Jahrbuch für Recht und Ethik (13), 2005, p. 519, quienes por eso fundamentan la excepción de manera más cauta.

52 El Informe de la Comisión Landau, IsLR (23), 1989, pp. 173 y s.; BRUGGER, Der Staat (35), 1996, p. 97, quien, como él mismo dice, alude a las "consecuencias más distantes" de la relativización de la prohibición de tortura, sin poder ofrecer respuestas sobre ellas; y especialmente, en particular, EL MISMO, en NITSCHKE (n. 7), pp. 114 y s. (a pesar del pasaje con el encabezamiento “¿rotura del dique hacia adentro y afuera?”); EL MISMO, Kreuz (n. 50), 167; DERSHOWITZ, Terrorism (n. 13), pp. 144 y s.; BREUER (n. 22), p. 91.

53 En particular ERB, NStZ, 2005, p. 601; EL MISMO, en NITSCHKE (n. 7), pp. 166 y s.; EL MISMO en LENZEN (n. 22), pp. 35 y s., también POSNER (n. 11), pp. 294 y s.; FAHL, JR, 2004, 189; WAGENLÄNDER (n. 22), pp. 167 y s. Ya es escandaloso el comentario de POSNER cit., según el cual los efectos corruptores para el país torturador no tendrían lugar si la tortura fuera ejercida en el extranjero. Seguramente debe entenderse ello como una provocación chistosa a la inversión que propone BRUGGER del argumento de la ruptura del dique, según la cual la prohibición de torturar tendría efectos negativos incontrolables (BRUGGER, Freiheit (n. 15), p. 70; EL MISMO en NITSCHKE (n. 7), p. 116, en cuanto a la afirmación de WITTRECKS de que por "razones de principio" no interesan las consecuencias cuando se trata de salvar la dignidad de la víctima (en BLASCHKE y otros (n. 15), p. 186), representa una contradicción con sus propias -y tal vez inconscientes- premisas consecuencialistas.

54 Véase ya arriba en la n. 5.

$55 \mathrm{Y}$, entonces, tampoco que el ejemplo se centre en la comunicación gráfica, sobre lo que señala la atención ULBRICH, "Die normative Kraft der Bilder: Zur Funktion des Bildhaften in der Diskussion über die Zulässigkeit staatlicher Folter", en NITSCHKE (n. 7), pp. 119 y ss., pp. 122 y 130-131.

56 Cfr., por ejemplo, los consecuencialístas HARE en SEN/WILLIAMS (n. 33), p. 25; TRAPP (n. 25), p. 456; PETTIT, "The Consequentialist Perspectiva", en BARON/PETTIT/SLOTE, Three Methods of Ethics, Malden entre otros, 1997, pp. 92 y ss., pp. 141 y s., 148; GESANG, Eine Verteidigung des Utilitarismus, 2003, pp. 98 y 123. Acerca de la cuestión de la tortura y del informe Landau KREMNITZER, IsLR (23), 1989, p. 277: "Sólo quien puede verse al mismo tiempo en ambos pares de zapatos - en los del torturador y en los del torturado- y sigue aceptando la conclusión de la comisión (en el sentido de la admisibilidad de la tortura en situaciones de necesidad -Luís GRECO-) es un verdadero partidario del informe".

57 De modo no sorprendente introduce BRUGGER sus nuevas versiones del caso de la bomba de relojería así: "El caso se ejecuta en la ciudad natal del lector" (JZ, 2000, p. 165). 
"inhumano" 58 insistir todavía en el carácter absoluto de la prohibición de tortura. Aquéllos, o sea, quienes conforme la tortura autorizada deben vivir bajo el miedo de convertirse en víctimas, no somos justamente nosotros, sino otros, por regla general, grupos étnicos minoritarios ${ }^{59}$, los cuales, por lo visto, carecerían aquí precisamente de importancia. Un bonito balance entre costes y beneficios, en el cual nosotros disfrutemos, sobre todo, de los beneficios y, ellos, sobre todo, soporten los costes.

Pero una segunda razón para la ligereza con la cual se considera la tortura en una situación semejante como la alternativa de comportamiento más beneficiosa, se atribuye, en parte, a la modificación de la actitud frente al Estado, modificación que también se refleja en las encuestas sobre la tortura ${ }^{60}$. Para el pensamiento liberal parece casi constitutiva una desconfianza sana frente al Estado ${ }^{61}$. Éste ni es el lugar, en el cual el ser humano logra y perfecciona su destino esencial ${ }^{62}$, ni la realización de la idea ético-moral objetivamente razonable ${ }^{63}$, sino, en primera línea, el Leviatán ${ }^{64}$, o sea, una amenaza constante para los derechos de sus sometidos. Sin embargo, esta actitud distanciada respecto del Estado parece estar cediendo hacia una considerable confianza, especialmente en los países del bienestar, de modo que ya no se teme frente a su amenaza, sino, exclusivamente, ante agrupaciones criminales o terroristas, o sea, agrupaciones ajenas al Estado ${ }^{65}$. Por consiguiente, el análisis aparentemente empírico de coste-beneficio propuesto por los partidarios de la excepción vive de una premisa ideológica, porque a través la historia ha quedado repetidamente refutada, según la cual habría que temer menos al Estado que a los particulares. Así afirma, de

58 Así, ERB, Jura, 2005, p. 30.

59 KAISER, "Folter, Misshandlung und krimineller Machtmissbrauch heute", KrimJ (35), 2003, pp. 243 y ss., p. 254.

60 Véase al respecto SCHNORR/WISSING, ZRP, 2003, p. 142, quienes toman estos resultados correctamente como "la expresión de una decadencia de los valores".

61 Así, correctamente, FERRAJOLI, Diritto e ragione, 5ª ed., Roma/Bari, 1998, p. 927.

62 Así, según, la interpretación habitual de ARISTOTELES, Politik (trad. por Rolfes), 1995, $1^{\circ}$ Libro Cap. II, y Christian WOLFF, Vernünftige Gedanken von dem gesellschaftlichen Leben der Menschen und insonderheit dem Gemeinen Wesen, Ed. Arndt, Hildesheim/New York, 1975, §§ 215 y ss., 218, 224; EL MISMO, Grundsätze des Natur und Völkerrechts, ed. Thomann, Hildesheim/New York, 1980, en particular el $§ 9$.

63 HEGEL, Grundlinien der Philosophie des Rechts, 1986, § 259. Contra esta interpretación tradicional de HEGEL como filósofo del Estado antiliberal (por todos, POPPER, The Open Society and its Enemies, t. 2, $5^{\mathrm{a}}$ ed., New Jersey, 1966, pp. 27 y ss. y HAYEK, The Counter-Revolution of Science, Indianapolis, 1952, pp. 367 y ss., en particular p. 399), se defiende una reciente interpretación, que estima el pensamiento de HEGEL como liberal (por ejemplo RAWLS, Lectures on the History of Moral Philosophy, Cambridge entre otros, 2000, pp. 352 y ss.) o como neutral desde el punto de vista político (cfr. PAWLIK, "Hegel und die Vernünftigkeit des Wirklichen", Der Staat (41), 2002, pp. 183 y ss., pp. 193 y s.).

64 HOBBES, Leviathan, ed. Tuck, Cambridge, 1996, passim.

65 Esto lo subraya con razón LÜDERSSEN (n. 36), p. 696: "los seres humanos...se han desacostumbrado a sentir miedo al Estado"; K. GÜNTHER (n. 51), p. 105; REEMTSMA (n. 9), p. 100. 
hecho, DERSHOWITZ en las primeras páginas de su libro: "Un principio importante de las libertades civiles es que los peligros más grandes a la libertad vienen del Estado poderoso. (...) El fenómeno relativamente nuevo de los grupos terroristas -organizaciones que, en sí mismas, no son Estados, pero que, sin embargo, hacen la guerra y procuran el acceso a armas de destrucción- desafía por primera vez ese paradigma. El nuevo paradigma -grupos terroristas capaces de causar estragos de la clase de los que anteriormente sólo podrían infligir los Estados, pero sin la responsabilidad de éstos- requiere a los libertarios civiles el replanteamiento sobre nuestra concentración en la acción del Estado"66. BRUGGER comienza uno de sus primeros artículos con la pregunta sobre si la prohibición de tortura sin excepción sería también válida, "cuando el Estado no es autoritario ni totalitario, sino que se encuentra organizado según el principio democrático y del Estado de Derecho y, en el caso concreto, persigue propósitos que, en sí tomados, parecen legítimos" ${ }^{67}$. Es posible encontrar más manifestaciones en este último sentido $^{68}$. Estas opiniones aparecen completamente incomprensibles si se tiene en cuenta todo lo que han hecho los Estados a lo largo de la historia, pero, especialmente, en la primera mitad del siglo XX. Comparado con ello, no sólo tiene poca importancia el 11 de septiembre (que en absoluto debe ser minimizado), sino que también nuestra bomba de relojería parece una pequeñez. Las amenazas terroristas, hasta el momento comprobadas de manera histórico-empírica, no suministran

66 DERSHOWITZ, Terrorism (n. 13), pp. 10 y s.

67 BRUGGER, Der Staat (35), 1996, p. 68 (cita), p. 82.

68 Por ejemplo, HILGENDORF, JZ, 2004, p. 331: "Sin embargo no debería pasarse por alto que hoy no está en debate el regreso a un Estado torturador totalitario..."; o la afirmación de WAGENLÄNDER (n. 22), pp. 167 y s., según la cual el permiso excepcional de la tortura no sería peligroso en un Estado de Derecho.

También la afirmación frecuente según la cual hoy no estaría en discusión la tortura tradicional, sino, únicamente, la tortura salvífica -Rettungsfolter- [por ejemplo, JEROUSCHEK/KÖLBEL, JZ, 2003, pp. 614 y s.; HILGENDORF, JZ, 2004, p. 331; BREUER (n. 22), pp. 16 y s.; JEROUSCHEK, JuS, 2005, pp. 297 y 300; en esta línea además SCHROEDER, ZRP, 2003, p. 180; WOLBERT (n. 50), p. 85; IPSEN (n. 7), p. 39; también ampliamente ISENSEE (n. 15), p. 60, LENZEN (n. 50), pp. 200 y s. [“tortura”]; TRAPP (n. 50), pp. 99 y ss., pp. 103 y ss. ("selbstsverschuldete Rettungsbefragungen") para quien en los casos de salvación ni siquiera se trataría de tortura; el huevo de Colón lo encontró ERB en NITSCHKE (n. 7), pp. 163 y s.; EL MISMO, en LENZEN (n. 22), p. 33, quien opina, que las convenciones de Derecho internacional público no habrían pensado quizás en los grupos de casos nuevos; de otra opinión resulta ideológico, sin embargo, DERSHOWITZ, Terrorism (n. 13), p. 157], puesto que sugiere que se trataría de un nuevo modo de tortura desconocido para nuestros antepasados, a la que no se le aplicaría el juicio tradicional de condenación [así también SCHILD (n. 7), p. 78]. Incluso la tortura de brujas fue finalmente una instancia de tortura salvífica, pues se trató de eso, de combatir los peligros para las almas de todos los hombres que provenían de quienes se suponía que por haber hecho un pacto con el demonio integraban su ejército, el de los enemigos de Dios [véase SCHILD (n. 7), p. 75 y s., 78 y s.]. Las prohibiciones jurídico-positivas sin excepciones no son otra cosa que una respuesta a las estrategias argumentativas desde hace tiempo conocidas, que quieren justificar la tortura también mediante la advertencia de la imprescindibilidad para el salvamento de bienes importantes [así también KREMNITZER, IsLR (23), 1989, p. 242; HECKER, KritJ (36), 2003, p. 213; JAHN, KritV, 2004, pp. 37 y s.; DORFMAN, “The tyranny of terror”, en LEVINSON (n. 2), pp. 3 y ss., p. 16; ENDERS (n. 15), p. 145; KINZIG, (n. 2), p. 19; HONG (n. 7), p. 25; MOLINA FERNÁNDEZ (n. 12), p. 280]. 


\section{Revisla de Perecho}

mucho fundamento para creer en el análisis de coste-beneficio defendido desde la opinión rechazada.

Las consideraciones recientemente formuladas contra el análisis de coste-beneficio sostenido por la opinión contraria son, naturalmente, especulaciones empíricas, las cuales se encuentran bajo un tipo de cláusula rebus sic stantibus. Una prohibición de la tortura para siempre inviolable, en consecuencia, absoluta, sólo puede fundamentarse por aquél que argumente, a la vez, desde el punto de vista deontológico y eso significa, también, libre de empirismo. Con todo, hay que concluir que ni siquiera los anteriores argumentos consecuencialistas de los defensores de la tortura pueden soportar sus conclusiones.

\section{Conclusión}

La diferenciación entre la situación normal y la situación de emergencia y la aceptación de que no deben parecerse las reglas vigentes en la situación normal y en la situación de emergencia no son sostenibles, puesto que toda regla trasciende a la situación. Más todavía: la excepción demuestra qué queremos decir seriamente con la regla. Esto no lo ha visto nadie con más claridad que el filósofo de la excepción, CARL SCHMITT, a pesar de su afirmación de que todo Derecho sería un Derecho de la situación cuya validez presupondría una situación normal determinada ${ }^{69}$ : "Lo normal no demuestra nada, la excepción prueba todo; ella confirma no sólo la regla, en realidad, la regla vive únicamente de la excepción"7o. Esto no puede esquivarse con la advertencia de la necesidad de una ética del caso excepcional ${ }^{71}$, del deber del estadista de abrirse a lo trágico de su misión y de ensuciarse las manos ${ }^{72}$ o por medio de una diferenciación entre el trato con los ciudadanos y el combate contra los enemigos ${ }^{73}$.

"La excepción prueba todo". Por consiguiente, sería inadecuado reprochar a la opinión aquí defendida el fetichismo a las reglas por a su

69 SCHMITT, Politische Theologie, $8^{\text {a }}$ ed., 2004, p. 19.

70 SCHMITT (n. 70), p. 21.

71 Véase, en particular, M. WALZER, Emergency Ethics, en Arguing about War, New Haven/London, 2004, pp. 33 y ss., p. 40; de acuerdo LEVINSON, Texas Law Review (81), 2003, p. 2032; similar GROSS (n. 10), p. 239, que diferencia entre una "perspectiva de política general" y una "perspectiva del caso catastrófico", y ZUCKERMANN, "Coercion and the Judicial Ascertainment of Truth”, IsLR (23), 1989, pp. 357 y ss., pp. 372 y s.; además TRAPP (n. 25), p. 459.

72 Véase aquí nuevamente M. WALZER, "Political Action: The Problem of Dirty Hands", Philosophy \& Public Affairs (2), 1972, pp. 160 y ss., pp. 166 y s.; también MOORE (n. 22), p. 720; ISENSEE, (n. 15), p. 61; y, secundariamente, ELSHTAIN, "Reflection on the Problem of "Dirty Hands", en LEVINSON (n. 2), pp. 77 y ss., p. 83.

73 Véase arriba n. 44. 
disposición a dejar morir seres humanos por el amor a unos "principios abstractos"74. La cuestión son siempre las reglas o los "principios abstractos". También los defensores de la excepción defienden reglas, únicamente otras, a saber: que la dignidad del ser humano puede decaer o que está sujeta a una reserva de costes; reglas que con frecuencia ni siquiera ellos quieren defender abiertamente, porque ellas tampoco son defendibles. La cuestión no consiste en si obedecemos reglas, la cuestión es, mejor dicho, qué reglas obedecemos: las reglas del Estado de Derecho que conocen límites absolutos en el trato con los seres humanos o las reglas de la gran banda de ladrones que puede saltarse, de manera desenfadada, tales obstáculos. El Estado de Derecho debe resistir incluso y, justamente, ante lo peor. Pues, como afirma ROXIN llegando al quid: "su superioridad moral frente al delincuente radica justamente en que el Estado no se sirve de los mismos métodos que éste"75.

"La regla vive, en realidad, únicamente de la excepción”: en la discusión sobre los casos de la bomba de relojería no se trata, finalmente, de nuestro comportamiento hipotético ante una situación conflictiva imaginada, que ojalá nunca ocurriera, sino de nuestro comportamiento actual y de las razones que lo sostienen, tanto de nuestra renuncia a la tortura así como también de nuestra condena a esta práctica. Por eso, proponer la excepción de la regla de la prohibición de la tortura significa que no se desestima la tortura porque lesiona la dignidad de un ser humano, sino por el contrario, porque éste todavía no se ha comportado mal o porque no tenemos ningún interés suficientemente fuerte para torturarlo. Sin embargo, al Estado de Derecho lo que le importa es la dignidad.

\footnotetext{
74 Así, sin embargo, FRANKE, "Wie verbindlich ist das Folterverbot für den Rechtstaat", en NITSCHKE (n. 6), pp. 51 y ss., p. 61; véase, además, ERB, Jura, 2005, p. 30; EL MISMO, NStZ, 2005, pp. 600 y s.; EL MISMO, en NITSCHKE (n. 7), p. 165; EL MISMO, en LENZ; BRUNKHORST (n. 22), p. 34 s., que habla aquí imprudentemente de "totalitarismo"; más refinado, pero, a pesar de ello, inaceptable ELSHTAIN (n. 73), pp. 83, 86 y s., quien reconduce la opinión aquí sostenida a la tradición teológica del pietismo rígido, y, por su parte, defiende la tradición católica de una casuística de la responsabilidad concreta.

75 Así, sin embargo, FRANKE, "Wie verbindlich ist das Folterverbot für den Rechtstaat", en NITSCHKE (n. 6), pp. 51 y ss., p. 61; véase, además, ERB, Jura, 2005, p. 30; EL MISMO, NStZ, 2005, pp. 600 y s.; EL MISMO, en NITSCHKE (n. 7), p. 165; EL MISMO, en LENZ; BRUNKHORST (n. 22), p. 34 s., que habla aquí imprudentemente de "totalitarismo"; más refinado, pero, a pesar de ello, inaceptable ELSHTAIN (n. 73), pp. 83, 86 y s., quien reconduce la opinión aquí sostenida a la tradición teológica del pietismo rígido, y, por su parte, defiende la tradición católica de una casuística de la responsabilidad concreta.
} 


\section{Bibliografía}

- Alexy, Theorie der juristischen Argumentation, 1983.

- Aristoteles, Politik (trad. por Rolfes), $1^{\circ}$ Libro Cap. II, 1995.

- Badura, "Generalprävention und Würde des Menschen", JZ, 1964, pp. 337 y ss.

- Beestermöller, "Folter - Daumenschrauben an der Würde des Menschen”, en Beestermöller/Brunkhorst (Ed.), Rückkehr der Folter, 2006, pp. 115 y ss.

- Bentham, "Of Torture; Of Compulsion and herein of Torture", en Twining/Twining, Northern Ireland Legal Quarterly 24, 1973, p. 305 ss.

- Bielefeldt, "Das Folterverbot im Rechtsstaat", en Nitschke (Ed.), Rettungsfolter im modernen Rechtstaat?, 2005, pp. 95 y ss.

- Bielefeldt, "Die Absolutheit des Folterverbots", en Beestermöller/ Brunkhorst(Ed.), Rückkehr der Folter, 2006, pp. 109 y ss.

- Birnbacher, "Ethisch ja, rechtlich nein - ein fauler Kompromiss?", en Lenzen (coord.), Ist Folter erlaubt?, 2006, pp. 135 y ss.

- Birnbacher, Analytische Einführung in die Ethik, 2003.

- Bossuyt, "Two New Regional Conventions with Respect to the Prohibition of Torture", en Matscher (Ed.), Folterverbot sowie Religionsfreiheit im Rechtsvergleich, 1990, pp. 81 y ss.

- Breuer, "Das Foltern von Menschen", en Beestermöller/Brunkhorst (Ed.), Rückkehr der Folter, 2006, pp. 11 y ss.

- Brieskorn, "Folter", en Beestermöller/Brunkhorst (Ed.), Rückkehr der Folter, 2006 p. 52.

- Brugger, "Darf der Staat ausnahmsweise foltern?”, Der Staat (35), 1996, pp. 66 y ss.

- Brugger, "Vom unbedingten Verbot der Folter zum bedingten Recht auf Folter?” JZ, 2000, pp. 165 y ss.,

- Brugger, Das anthropologische Kreuz der Entscheidung in Politik und Recht, 2005.

- Brugger, en Brugger /Schlink Darf der Staat foltern? - Eine Podiumsdiskussion, HFR 2002, Beitrag 4, 2002, p. 8;

- Brugger, Freiheit und Sicherheit, 2004.

- Brugger, Menschenwürde, Menschenrechte, Grundrechte, 1997.

- Brugger,"Das andere Auge. Folter als zweitschlechteste Lösung”, en Nitschke (Ed.), Rettungsfolter im modernen Rechtstaat?, 2005, pp. 107 y ss.

- Brunkhorst, "Folter, Würde und repressiver Liberalismus", en Beestermöller/Brunkhorst (Ed.), Rückkehr der Folter, 2006, pp. 88 y ss. 
- $\quad$ BVerfGE 87, 228.

- BVerfGE 87, 228.

- Christensen, "Wahrheit, Recht und Folter - Eine methodische Betrachtung”, en Blaschke y otros (Ed.), Sicherheit oder Freiheit?, 2005, pp. 133 y ss.

- Christian Wolff, Grundsätze des Natur und Völkerrechts, ed. Thomann, Hildesheim/New York 1980, en particular el § 9.

- Christian Wolff, Vernünftige Gedanken von dem gesellschaftlichen Leben der Menschen und insonderheit dem Gemeinen Wesen, Ed. Arndt, Hildesheim/New York, 1975, §§ 215 y ss., 218, 224;

- Dershowitz, "Is it Necessary to Apply "Physical Pressure" to Terrorists - and to Lie about it?” IsLR (23), 1989, pp. 192 y ss.

- Dershowitz, "Tortured reasoning", en Levinson (Ed.), Torture - A collection, Oxford/New York, 2004, pp. 257 y ss.

- Dershowitz, Why terrorism works, New Haven/London, 2002.

- Dorfman, "The tyranny of terror", en Levinson (Ed.), Torture - A collection, Oxford/New York, 2004, pp. 3 y ss.

- Dürig, "Der Grundrechtssatz von der Menschenwürde", AöR (81), 1956, pp. 117 y ss.

- Düx, ZRP, 2002, pp. 180 y ss.

- Ehrlich/Johannsen, “Folter im Dienste der Sicherheit?”, en Hasse y otros (Ed.), Menschenrechte, 2002, pp. 332 y ss.

- Ellbogen, "Zur Unzulässigkeit der Folter (auch) im präventiven Bereich”, Jura, 2005, pp. 339 y ss.

- Elshtain, "Reflection on the Problem of "Dirty Hands"”, en Levinson (Ed.), Torture - A collection, Oxford/New York, 2004, pp. 77 y ss.

- Enders, "La dignidad del Estado de Derecho reside en la dignidad del ser humano -Das absolute Verbot staatlicher Folter", en Nitschke (Ed.), Rettungsfolter im modernen Rechtstaat?, 2005, pp. 133 y ss.

- Erb, "Nothilfe durch Folter", Jura, 2005, pp. 24 y ss., p. 27;

- Erb, "Notwehr als Menschenrecht”, NStZ 2005, pp. 593 y ss.

- Erb, § 32/173 y s.,en Münchener Kommentar zum Strafgesetzbuch, 2003.

- Erb, en Lenzen(coord.), Ist Folter erlaubt?, 2006, p. 19 y ss.

- Erb, en Nitschke (Ed.), Rettungsfolter im modernen Rechtstaat?, 2005, pp. 149 y ss.

- Esser, "Die menschenrechtliche Konzeption des Folterverbotes im deutschen Strafverfahren”, en Gehl (Ed.), Folter - Zulässiges Instrument im Rechtsstaat?, 2005, pp. 143 y ss.

- Fahl, "Angewandte Rechtsphilosophie - "Darf der Staat foltern?””, JR, 2004, pp. 182 y ss. 
- Ferrajoli, Diritto e ragione, $5^{\text {a }}$ ed., Roma/Bari, 1998.

- Franke, "Wie verbindlich ist das Folterverbot für den Rechtstaat", en Nitschke (Ed.), Rettungsfolter im modernen Rechtstaat?, 2005, pp. 51 y ss.

- Frankenberg, "Kritik des Bekämpfungsrechts", KritJ (38), 2005, pp. 370 y ss.

- Gaede, "Die Fragilität des Folterverbots", en Camprubi (Ed.), Angst und Streben nach Sicherheit in Gesetzgebung und Praxis, 2004, pp. $155 \mathrm{y}$ ss.

- Gebauer "Zur Grundlage des absoluten Folterverbots", NVwZ, 2004, pp. 1405 y ss.

- Gesang, Eine Verteidigung des Utilitarismus, 2003.

- Góngora Mera, “"Ein bisschen Folter”: Alemania debate sobre la tortura", (http://www.menschenrechte.org/beitraege menschenrechte/debate_tortura.htm)

- Götz, "Das Urteil gegen Daschner im Lichte der Werteordnung des Grundgesetzes", NJW, 2005, pp. 953 y ss.

- Greco, “Über das sogenannte Feindstrafrecht”, GA, 2006, pp. 96 y ss.

- Gross, "The Prohibitions on Torture and the Limits of the Law", en Levinson (Ed.), Torture - A collection, Oxford/New York, 2004, pp. 229 y ss.

- Guckelberger, "Zulässigkeit von Polizeifolter?", VBlBW, 2004, pp. 121 y ss.;

- Gur-Arye, "Can the War against Terror justify the Use of Force in Interrogations?" en Levinson (Ed.), Torture - A collection, Oxford/ New York, 2004, pp. 183 y ss.

- Gusy, “Christian Thomasius: Über die Folter, 1705”, NJW, 2005, pp. 239 y ss., p. 240;

- Häberle, "Die Menschenwürde als Grundlage der staatlichen Gemeinschaft", en Isensee/Kirchhof (Ed.), Handbuch des Staatsrechts, t. I, 1987, § 20/44.

- Habermas, Diskursethik - Notizen zu einem Begründungsprogramm, en Moralbewußtsein und kommunikatives Handeln, $7^{\mathrm{a}}$ ed., 1997.

- Hamm, "Schluss der Debatte über Ausnahmen vom Folterverbot!", NJW, 2003, p. 946.

- Hare, The Language of Morals, Oxford, 1952.

- Hare,"Ethical Theory and Utilitarianism", en Sen/Williams (Ed.), Utilitarianism and Beyond, Cambridge, 1982, pp. 23 y ss.

- Hassemer, "Sicherheit durch Strafrecht", StV, 2006, pp. 321 y ss.

- Hassemer, "Unverfügbares im Strafprozeß", en Festschrift für Maihofer, 1988, pp. 183 y ss.

- Haurand/Vahle, "Rechtliche Aspekte der Gefahrenabwehr in Entführungsfällen”, NVwZ, 2003, pp. 514 y s.

- Hayek, The Counter-Revolution of Science, Indianapolis, 1952. 


\section{Revisla de Derecho}

- Hecker, "Relativierung des Folterverbots in der BRD?", KritJ (36), 2003, pp. 210 y ss.

- Hegel, Grundlinien der Philosophie des Rechts, 1986.

- Herzberg, "Folter und Menschenwürde", JZ, 2005, pp. 321 ss.

- Hetzer, "Ist Freiheit durch Sicherheit korrumpierbar?", en StraFo, 2006, pp. 140 y ss.

- Hilgendorf, “Folter im Rechtsstaat?”, JZ, 2004, pp. 331 y ss.

- Hobbes, Leviathan, ed. Tuck, Cambridge, 1996.

- Höffe, Kategorische Rechtsprinzipien, 1990.

- Hong, "Das grundgesetzliche Folterverbot und der Menschenwürdegehalt der Grundrechte", en Beestermöller/ BRUNKHORST (Ed.), Rückkehr der Folter, 2006, pp. 24 y ss.

- Hruschka, "Die Würde des Menschen bei Kant", ARSP (88), 2002, pp. 463 y ss.

- Ignatieff, The Lesser Evil. Political Ethics in an Age of Terror, Edinburgh, 2005.

- Informe de la Comisión Landau (1989), en Israel Law Review, 1989, pp. 146 y ss.

- Ipsen, "Folterverbot und Notwehrrecht", en Lenzen (coord.), Ist Folter erlaubt? 2006, pp. 38 y ss.

- Isensee, Tabu im freiheitlichen Staat, 2003.

- J. Schulz, "Das Folterverbot der EMRK und seine Auswirkungen auf das Strafrecht”, en Lenzen (coord.), Ist Folter erlaubt? 2006, pp. 77 y SS.

- Jackson en 337 U. S. 1, 37 (1949)

- Jaeger, "Folterdebatte - es gibt kein schwarz oder weiß", en Gehl (Ed.), Folter - Zulässiges Instrument im Rechtsstaat?, 2005, pp. 29 y ss.

- Jahn, “Gute Folter - Schlechte Folter?", KritV, 2004, pp. 24 y ss.

- Jahn, Das Strafrecht des Staatsnotstandes, 2004.

- Jakobs, "Bürgerstrafrecht und Feindstrafrecht", HRRS, 2004, pp. 88 y ss.

- Jakobs, “Terroristen als Personen im Recht?”, ZStW (117), 2005, pp. 839 y ss.

- Jerouschek, "Gefahrenabwendungsfolter - Rechtsstaatliches Tabu oder polizeirechtlich legitimierter Zwangseinsatz?”, JuS, 2005, pp. 296 y ss.

- Jerouschek/Kölbel, “Folter von Staats wegen?”, JZ, 2003, pp. 619 y s.

- Jeßberger, "Wenn du nicht redest, füge ich Dir große Schmerzen zu", Jura, 2003, pp. 711 y ss.

- Joerden, "Über ein vermeintliches Recht (des Staates), aus Menschenliebe zu foltern", Jahrbuch für Recht und Ethik (13), 2005, pp. 495 y ss.

- K. Günther, “Darf der Staat foltern, um Menschenleben zu retten?", en Beestermöller/Brunkhorst(Ed.), Rückkehr der Folter, 2006, pp. 101 y ss. 
- Kadish, “Torture, the State and the Individual”, IsLR (23), 1989, pp. 345 y ss.

- Kaiser, "Folter, Misshandlung und krimineller Machtmissbrauch heute", KrimJ (35), 2003, pp. 243 y ss.

- Kinzig, "Not kennt kein Gebot? “, en GEHL (Ed.), Folter - Zulässiges Instrument im Rechtsstaat? 2005, pp. 11 y ss.

- Kramer, "Wunsch nach Folter", KritJ (33), 2000, pp. 624 y ss.

- Kremnitzer, "The Landau Commission Report", IsLR (23), 1989, pp. 216 y ss.

- Kretschmer, "Folter in Deutschland", RuP, 2003, pp. 102 y ss.

- Kreuzer, "Zur Not ein bisschen Folter?" en Nitschke(Ed.), Rettungsfolter im modernen Rechtstaat?, 2005, p. 44

- Kühl, Strafrecht Allgemeiner Teil, $5^{\mathrm{a}}$ ed., 2005, § 7/156a.

- La decisión del Tribunal Superior Israelí publicado en Levinson (Ed.), Torture - A collection, Oxford/New York 2004 pp. 165 y ss.

- Lackner/Kühl, § 32/17a, en Lackner/Kühl StGB $25^{\text {a }}$ ed., 2004.

- Lenckner, § 34/41e, en Schönke/Schröder StGB, $27^{\mathrm{a}}$ ed., 2006.

- Lenzen, “"Folter”, Menschenwürde und das Recht auf Leben”, en Lenzen(coord.), Ist Folter erlaubt?, 2006, pp. 200 y ss.

- Levinson, "“Precommitment" and "Postcommitment": The Ban on Torture in the Wake of September 11", Texas Law Review (81), 2003, pp. 2013 y ss.

- LG Frankfurt, NJW (10), 2005, pp. 692-696

- Lübbe, "Konsequenzialismus und Folter", en Lenzen (coord.), Ist Folter erlaubt? 2006, pp. 67 y ss.

- Lüderssen, "Die Folter bleibt Tabu", en Festschrift für Rudolphi, 2004, pp. 691 y ss.

- Luhmann, Gibt es in unserer Gesellschaft noch unverzichtbare Normen? 1993.

- M. Walzer, "Political Action: The Problem of Dirty Hands", Philosophy \& Public Affairs (2), 1972, pp. 160 y ss.

- M. Walzer, Emergency Ethics, en Arguing about War, New Haven/ London, 2004.

- Merten, "Folterverbot und Grundrechtsdogmatik", JR, 2003, pp. 404 y ss.

- Miehe, "Nochmals: Die Debatte über Ausnahmen vom Folterverbot", NJW, 2003, pp. 1219 y s.

- Molina Fernández, "La ponderación de intereses en situaciones de necesidad extrema: ces justificable la tortura?”, en Cuerda Riezu (Ed.), La respuesta del Derecho ante los nuevos retos, 2006, pp. 265 y ss.

- Moore, "Torture and the Balance of Evils," en Placing Blame, Oxford, 1997. 
- Morgan, "The Utilitarian Justification of Torture", Punishment and Society (2), 2000, pp. 181 y ss.

- Neuhaus, "Die Aussageerpressung zur Rettung des Entführten: strafbar!", GA, 2004, pp. 521 y ss.;

- Neumann, "Die Moral des Rechts", Jahrbuch für Recht und Ethik (2), 1994, pp. 81 y ss.

- Neumann, "Die Tyrannei der Würde”, ARSP (84), 1998, pp. 153 y ss.

- Neumann, "Moralphilosophie und Strafrechtsdogmatik", ARSP (44), 1991, pp. 248 y ss.

- Norouzi, “Folter in Nothilfe - geboten?”, JA, 2005, pp. 306 y ss.

- Norris Lance/Little, "Defending Moral Particularism", en J. Dreier (Ed.), Contemporary Debates in Moral Theory, Malden, 2006, pp. 305 y ss.

- Otto, "Diskurs über Gerechtigkeit, Menschenwürde und Menschenrechte", JZ, 2005, pp. 473 y ss.

- Otto, Grundkurs Strafrecht, $7^{\mathrm{a}}$ ed., 2004, § 8/59

- Parry, "Escalation and Necessity", en Levinson (Ed.), Torture - A collection, Oxford/New York, 2004, pp. 145 y ss.,

- Pawlik, "Hegel und die Vernünftigkeit des Wirklichen", Der Staat (41), 2002, pp. 183 y ss.

- Perron, “Foltern in Notwehr?” Festschrift U. Weber, 2004, pp. 143 y ss.

- Pettit, "The Consequentialist Perspectiva", en Baron/Pettit/Slote, Three Methods of Ethics, Malden y otros, 1997, pp. 92 y ss.

- Polaino-Orts, Derecho Penal del Enemigo, Lima, 2006.

- POPPER, The Open Society and its Enemies, t. 2, $5^{\mathrm{a}}$ ed., New Jersey, 1966.

- Poscher, "Menschenwürde als Tabu", en Beestermöller/ Brunkhorst(Ed.), Rückkehr der Folter, 2006, pp. 75 y ss.

- Poscher, "Menschenwürde im Staatsnotstand", en Lenzen (coord.), Ist Folter erlaubt?, 2006, pp. 47 y ss., p. $61 \mathrm{s.}$

- Posner, "Torture, Terrorism, and Interrogation", en Levinson (Ed.), Torture - A collection, Oxford/New York, 2004, pp. 291 y ss., p. 296

- R. Marx, "Folter: eine zulässige Polizeiliche Präventionsmassnahme?" en Gehl (Ed.), Folter - Zulässiges Instrument im Rechtsstaat? 2005, pp. 95 y ss.

- R. Marx, "Globaler Krieg gegen den Terrorismus und territorial gebrochene Menschenrechte", KritJ (39), 2006, pp. 151 Y SS.

- Raess, Der Schutz vor Folter im Völkerrecht, 1989.

- Rawls, Lectures on the History of Moral Philosophy, Cambridge, 2000. 
- Reemtsma, "Wir sind alles für Dich”, en Reemtsma (Ed.), Folter, 1991, pp. 7 y ss.

- Reemtsma, "Zur Diskussion über die Re-Legitimierung der Folter", en Beestermöller/Brunkhorst (Ed.), Rückkehr der Folter, 2006, pp. 71 y s.

- Reemtsma, Folter im Rechtsstaat, 2005.

- Robinson, "Letter to the Editor", IsLR (23), 1989, pp. 189 y SS...

- Roxin, "Kann staatliche Folter in Ausnahmefällen zulässig oder wenigstens straflos sein?”, en Festschrift für Eser, 2005, pp. 461 y ss.

- Roxin, "Rettungsfolter?" en Festschrift für Nehm, 2006, pp. 161 y ss.,

- $\quad$ Roxin, Strafrecht, Allgemeiner Teil, t. I, $4^{\mathrm{a}}$ ed., 2006, § 22/169;

- Saliger, “Absolutes im Strafprozeß?” ZStW (116), 2004, pp. 35 y ss.

- Saliger,"Feindstrafrecht:KritischesodertotalitäresStrafrechtskonzept?” JZ, 2006, pp. 756 y ss.

- Scarry, "Five Errors in the Reasoning of Alan Dershowitz", en Levinson (Ed.), Torture - A collection, Oxford/New York, 2004, pp. 281 y ss.

- Schaefer, "Freibrief", NJW, 2003, p. 947.

- Schild, "Folter (androhung) als Straftat", en Gehl (Ed.), Folter Zulässiges Instrument im Rechtsstaat? 2005, pp. 59 y ss.

- Schild, "Folter einst und jetzt", en Nitschke (Ed.), Rettungsfolter im modernen Rechtstaat? 2005, pp. 69 y ss.,

- Schlehofer, "Die Menschenwürdegarantie des Grundgesetzes absolute oder relative Begrenzung staatlicher Strafgewalt?”, GA, 1999, pp. 357 y ss.

- Schlink, en Brugger/Schlink, Darf der Staat foltern? - Eine Podiumsdiskussion, HFR 2002, Beitrag 4, p. 6.

- Schmitt, Politische Theologie, $8^{\mathrm{a}}$ ed., 2004.

- Schnorr/Wissing, ZRP, 2003, p. 142

- Schroeder, ZRP, 2003, p. 180;

- Schünemann, "Feindstrafrecht ist kein Strafrecht", Festschrift für Nehm, 2006, pp. 219 y ss.

- Shue, "Torture”, en Levinson (Ed.), Torture - A collection, Oxford/ New York, 2004, pp. 47 ss.

- Spirakos, Folter als Problem des Strafrechts, 1990.

- Steinhoff, "Warum Folter manchmal moralisch erlaubt, ihre Institutionalisierung durch Folterbefehle aber moralisch unzulässig ist”, en Lenzen (coord.), Ist Folter erlaubt?, 2006, pp. 173 y ss.

- Stobbe, "Die Unmenschlichkeit der Folter", en Beestermöller/ Brunkhorst (Ed.), Rückkehr der Folter, 2006, pp. 36 y ss.

- Tomuschat, "Rechtlicher Schutz gegen Folter", en Schulz-Hageleit (Ed.), Alltag-Macht-Folter, 1989, pp. 95 y ss. 
- Trapp, "Individualrechte ernst - aber nicht unangemessen ernst genommen“, en Nida-Rümelin/Vossenkuhl (Ed.), Ethische und politische Freiheit, 1997, pp. 448 y ss., p. 463.

- Trapp, "Wirklich Folter oder nicht vielmehr selbstverschuldete Rettungsbefragung?”, en Lenzen (coord.), Ist Folter erlaubt?, 2006, pp. 95 y ss.

- Ulbrich, "Die normative Kraft der Bilder: Zur Funktion des Bildhaften in der Diskussion über die Zulässigkeit staatlicher Folter", en Nitschke(Ed.), Rettungsfolter im modernen Rechtstaat?, 2005, pp. 119 y ss.

- von der Pfordten, "Ist staatliche Folter als fernwirkende Nothilfe ethisch erlaubt?”, en Lenzen (coord.), Ist Folter erlaubt?, 2006, pp. 149 ss.

- Wagenländer, Zur strafrechtlichen Beurteilung der Rettungsfolter, 2006.

- Wahl/Masing, "Schutz durch Eingriff", JZ, 1990, pp. 553 y ss.

- Welsch, "Die Wiederkehr der Folter als das letzte Verteidigungsmittel des Rechtsstaates?”, BayVBl, 2003, pp. 481 y ss.

- Wetz, “Die Würde des Menschen - Ein Phantom?”, ARSP (87), 2001, pp. 311 y ss.

- Wimmer, Universalisierung en der Ethik, 1980.

- Wittreck en Gehl (Ed.), Folter - Zulässiges Instrument im Rechtsstaat?, 2005, pp. 50 y ss

- Wittreck, "Achtungs- gegen Schutzpflicht? Zur Diskussion und Menschenwürde und Folterverbot”, en Blaschke y otros (Ed.), Sicherheit oder Freiheit?, 2005, pp. 161 y ss.

- Wittreck, "Menschenwürde als Foltererlaubnis?", en Gehl (Ed.), Folter - Zulässiges Instrument im Rechtsstaat?, 2005, pp. 37 y ss., p. 45;

- Wittreck, "Menschenwürde und Folterverbot", DöV, 2003, pp. .873 y ss., p.

- Wittreck, en Blaschke y otros (Ed.), Sicherheit oder Freiheit?, 2005, pp. 177 y s.

- Wolbert, “Ausnahmsloses Verbot der Folter?” en Gehl (Ed.), Folter Zulässiges Instrument im Rechtsstaat? 2005, pp. 93 y s.

- Zamir, "Human Rights and National Security", IsLR (23), 1989, pp. 375 y ss.

- Zeller, "Not actual "necessity" but possible "justification"; not "moderate" pressure, but either "unlimited" or "none at all", IsLR (23), 1989, pp. 201 y ss.

- Ziegler, "Das Folterverbot in der polizeilichen Praxis", KritV, 2004, pp. 50 y ss.

- Zizek, Welcome to the desert of the real, London/New York 2002, p. 103

- Zuckermann, "Coercion and the Judicial Ascertainment of Truth", IsLR (23), 1989, pp. 357 y ss. 
<smiles>[Si]#[Si]</smiles> 